OPEN ACCESS

Edited by:

Francesco Moccia,

University of Pavia, Italy

Reviewed by:

Brenda Bartnik-Olson,

Loma Linda University, United States

Dmitry Lim

Università degli Studi del Piemonte

Orientale, Italy

*Correspondence:

Juliette Piquet

juliette-piquet@hotmail.fr

Bruno Cauli

bruno.cauli@upmc.fr

Received: 27 November 2017 Accepted: 29 June 2018 Published: 18 July 2018

Citation:

Piquet J, Toussay X, Hepp R Lerchundi R, Le Douce J, Faivre É, Guiot $E$, Bonvento $G$ and Cauli B (2018) Supragranular Pyramidal Cells

Exhibit Early Metabolic Alterations in the 3xTg-AD Mouse Mode of Alzheimer's Disease.

Front. Cell. Neurosci. 12:216. doi: 10.3389/fncel.2018.00216

\section{Supragranular Pyramidal Cells Exhibit Early Metabolic Alterations in the 3xTg-AD Mouse Model of Alzheimer's Disease}

\author{
Juliette Piquet ${ }^{1 *}$, Xavier Toussay ${ }^{1}$, Régine Hepp ${ }^{1}$, Rodrigo Lerchundi2, \\ Juliette Le Douce ${ }^{2}$, Émilie Faivre ${ }^{2}$, Elvire Guiot ${ }^{1}$, Gilles Bonvento ${ }^{2}$ and Bruno Cauli ${ }^{1 *}$
}

1 UPMC Univ Paris 06, INSERM, CNRS, Neuroscience Paris Seine - Institut de Biologie Paris Seine (NPS - IBPS), Sorbonne Université, Paris, France, ${ }^{2}$ CNRS UMR 9199, Commissariat à l'Énergie Atomique et aux Énergies Alternatives (CEA), Département de la Recherche Fondamentale (DRF), Institut de Biologie François Jacob, Molecular Imaging Center (MIRCen), Université Paris-Sud, Université Paris-Saclay, Paris, France

The impairment of cerebral glucose utilization is an early and predictive biomarker of Alzheimer's disease (AD) that is likely to contribute to memory and cognition disorders during the progression of the pathology. Yet, the cellular and molecular mechanisms underlying these metabolic alterations remain poorly understood. Here we studied the glucose metabolism of supragranular pyramidal cells at an early presymptomatic developmental stage in non-transgenic (non-Tg) and 3xTg-AD mice, a mouse model of $A D$ replicating numerous hallmarks of the disease. We performed both intracellular glucose imaging with a genetically encoded fluorescence resonance energy transfer (FRET)-based glucose biosensor and transcriptomic profiling of key molecular elements of glucose metabolism with single-cell multiplex RT-PCR (scRT-mPCR). We found that juvenile pyramidal cells exhibit active glycolysis and pentose phosphate pathway at rest that are respectively enhanced and impaired in 3xTg-AD mice without alteration of neuronal glucose uptake or transcriptional modification. Given the importance of glucose metabolism for neuronal survival, these early alterations could initiate or at least contribute to the later neuronal dysfunction of pyramidal cells in AD.

Keywords: glucose uptake, glycolysis, pentose phosphate pathway, FRET imaging, single-cell RT-PCR

\section{INTRODUCTION}

Alzheimer's disease $(\mathrm{AD})$ is a neurodegenerative disorder characterized by progressive cognitive impairment and memory loss. The underlying neuropathology includes brain deposition of amyloid plaques formed by misfolded amyloid- $\beta(\mathrm{A} \beta)$, neurofibrillary tangles and neuronal loss (Braak and Braak, 1991; Hardy and Selkoe, 2002). The visualization by 18-fluoro-2-deoxy-Dglucose positron emission tomography of a decreased cerebral glucose utilization occurring in specific brain regions is one of the earliest functional signs of AD (Small et al., 2000; Dubois et al., 2016). It aggravates with the disease progression and even predicts the neuropathological diagnosis of $\mathrm{AD}$ (Mosconi, 2005; Mosconi et al., 2010).

The most vulnerable brain regions to $A \beta$ deposition corresponds to areas where glucose is physiologically used beside its role as a substrate for oxidative phosphorylation in spite of oxygen availability (Vaishnavi et al., 2010; Vlassenko et al., 2010). This non-oxidative glucose utilization is 
referred to as "aerobic glycolysis" and includes the glycolysis itself, the pentose phosphate shunt and the glycogen synthesis. Under physiological conditions, these glucose metabolic pathways are highly compartmentalized between neurons and glial cells, glycolysis, and glycogen synthesis occurring mainly in astrocytes (Allaman et al., 2011; Fernandez-Fernandez et al., 2012).

Deregulation of the neuronal metabolic program can be deleterious since hyperactive glycolysis and glycogen synthesis in neurons are pro-apoptotic (Vilchez et al., 2007; HerreroMendez et al., 2009). In addition, the pentose phosphate pathway promotes long-term neuronal survival (Vaughn and Deshmukh, 2008) and the non-oxidative use of glucose in the hexosamine biosynthetic pathway protects tau protein from hyperphosphorylation and restricts neurofibrillary tangles formation (Liu et al., 2009). Hence, an early alteration of neuronal glucose metabolism is likely to initiate or at least contribute to later neural dysfunctions and neurodegenerative processes characteristic of AD.

Although in vivo studies are considered as the reference standard to measure glucose metabolism (Sokoloff et al., 1977; Fox and Raichle, 1986; Fox et al., 1988), they generally lack the required resolution to investigate cellular processes and offer limited pharmacological investigations (Sotelo-Hitschfeld et al., 2015; Diaz-Garcia et al., 2017). Conversely, in vitro models provide an excellent spatial and temporal resolution but are largely based on culture systems derived from embryonic or neonate animals (Bittner C.X. et al., 2010; Surin et al., 2012; Tantama et al., 2013; Lerchundi et al., 2015). Given that brain metabolism undergoes substantial changes during embryonic and postnatal development (Bilger and Nehlig, 1992; Nehlig and Pereira de Vasconcelos, 1993; Nehlig, 1999; Surin et al., 2012) these in vitro models may not be appropriate to study age-related neurological disorders. The acute slice (ex vivo) models provide an intermediate approach preserving the cytoarchitecture of brain tissues also allowing cell-type specific investigations (Kasischke et al., 2004; Choi et al., 2012; Sotelo-Hitschfeld et al., 2015; Diaz-Garcia et al., 2017) but require careful design of experimental conditions (Iadecola and Nedergaard, 2007).

3xTg-AD mice is a model that replicates the neuropathological hallmarks of AD (Oddo et al., 2003; Carroll et al., 2010). In these mice, glucose metabolic impairments are already observed during embryogenesis (Yao et al., 2009) and progress during aging, thus preceding the apparition of $A \beta$ deposition and tau hyperphosphorylation (Nicholson et al., 2010; Ding et al., 2013; Sancheti et al., 2014a,b; Sanguinetti et al., 2018). Since cerebral metabolism switches from ketone bodies to glucose utilization during the first postnatal weeks (Bilger and Nehlig, 1992; Nehlig and Pereira de Vasconcelos, 1993; Nehlig, 1999) this developmental stage might represent a critical step in the emergence of glucose metabolism alterations. Layer II and III pyramidal neurons already contribute to glucose supply via neurovascular interactions during this period (Cauli and Hamel, 2010; Lecrux et al., 2011; Lacroix et al., 2015) and have been reported to degenerate before $\mathrm{A} \beta$ deposition in $3 \mathrm{xTg}-\mathrm{AD}$ mice (Bittner T. et al., 2010), suggesting an early involvement in the pathogenesis of $\mathrm{AD}$. We therefore underwent our investigations at a presymptomatic juvenile stage corresponding to the developmental metabolic switch by comparing the metabolic program of supragranular pyramidal neurons of non- $\mathrm{Tg}$ and $3 \times \mathrm{Tg}-\mathrm{AD}$ mice.

We used a genetically encoded fluorescence resonance energy transfer (FRET)-based glucose biosensor (Deuschle et al., 2005; Takanaga et al., 2008; Bittner C.X. et al., 2010) to investigate the uptake and fate of glucose at a cellular resolution and singlecell multiplex RT-PCR (scRT-mPCR) to determine the expression profiles of key elements of glucose metabolism of pyramidal cells. We report that both glycolysis and pentose phosphate pathways are active in juvenile pyramidal cells at rest. These fluxes are respectively enhanced and reduced in 3xTg-AD mice, without alteration of neuronal glucose uptake or transcriptional modification.

\section{MATERIALS AND METHODS}

\section{Animals}

Homozygous 3xTg-AD (MMRRC \#034830) generated and maintained on a mixed J29/C57BL6 background and wild type non-transgenic mice of the same background as well as C57BL6 background (11-19 postnatal days) of both genders were used for glucose imaging and patch-clamp recordings in acute slices. $3 \mathrm{xTg}-\mathrm{AD}$ mice express the mutated gene PS1M146V (knock-in) and the mutated human genes APPSwe and tauP301L in the same locus, both under the control of the mouse Thy1.2 regulatory element and were routinely genotyped by PCR (Oddo et al., 2003). All animals were housed in a temperature-controlled (21$25^{\circ} \mathrm{C}$ ) room under $12 \mathrm{~h}$ light: $12 \mathrm{~h}$ dark conditions and were given food and water ad libitum. A maximum of five mice were housed per cage and single animal housing was avoided. All experimental procedures using animals were performed in strict accordance with French regulations (Code Rural R214/87 to R214/130) R214/126 and conformed to the ethical guidelines of both the European Economic Community (86/609/EEC) and the French National Charter on the ethics of animal experimentation. All protocols were approved by the Charles Darwin ethics committee and submitted to the French Ministry of Education and Research (Approval 2015061011367540 APAFIS\#573-2015061011367547 v1). The IBPS animal facility is accredited by the French authorities (A75-05-24).

\section{Subcloning and Viral Production}

The glucose sensor FLII ${ }^{12}$ Pglu-700 $4 \delta 6$ (Takanaga et al., 2008) was used in this study. The coding sequence of the sensor was subcloned into the viral vector pSinRep5 (Invitrogen). Sindbis virus were produced as previously described (Hepp et al., 2007; Hu et al., 2011). Recombinant pSinRep5 and helper plasmid pDH26S were transcribed in vitro into capped RNA using the Megascript SP6 kit (Ambion). Baby hamster kidney-21 (ATGC \#CCL-10) cells were electroporated with sensor-containing RNA and helper RNA $\left(2 \times 10^{7}\right.$ cells, $\left.950 \mu \mathrm{F}, 230 \mathrm{~V}\right)$ and incubated for $24 \mathrm{~h}$ at $37^{\circ} \mathrm{C}$ in $5 \% \mathrm{CO}_{2}$ in Dulbecco's modified Eagle Medium supplemented with $5 \%$ fetal calf serum before collecting cell 
supernatant containing the viruses. The virus titer $\left(10^{8}\right.$ infectious particles/ml) was determined after counting fluorescent baby hamster kidney cells infected using serial dilution of the stock virus.

\section{Slice Preparation}

Mice were deeply anesthetized with isoflurane. After decapitation brains were quickly removed and placed into cold $\left(\sim 4^{\circ} \mathrm{C}\right)$ oxygenated artificial cerebrospinal fluid (aCSF) containing (in mM): $126 \mathrm{NaCl}, 2.5 \mathrm{KCl}, 1.25 \mathrm{NaH}_{2} \mathrm{PO}_{4}, 2 \mathrm{CaCl}_{2}, 1 \mathrm{MgCl}_{2}, 26$ $\mathrm{NaHCO}_{3}, 10$ glucose, 15 sucrose, and 1 kynurenic acid (Sigma). Coronal slices (300 $\mu \mathrm{m}$ thick) containing the barrel cortex were cut with a vibratome (VT1000S; Leica) and allowed to recover at room temperature for at least $1 \mathrm{~h}$ in aCSF saturated with $\mathrm{O}_{2} / \mathrm{CO}_{2}$ (95\%/5\%) as previously described (Karagiannis et al., 2009).

\section{Brain Slice Viral Infection}

Brain slices were placed onto a millicell-CM membrane (Millipore) with culture medium (50\% minimum essential medium, 50\% Hank's balanced salt sodium, $6.5 \mathrm{~g} / \mathrm{l}$ glucose $(\sim 36 \mathrm{mM})$, and $100 \mathrm{U} / \mathrm{ml}$ penicillin/100 $\mu \mathrm{g} / \mathrm{ml}$ streptomycin; Invitrogen) as previously described (Drobac et al., 2010; Hu et al., 2011). Infection was performed by adding $\sim 5 \times 10^{5}$ particles per slice. Slices were incubated overnight at $35^{\circ} \mathrm{C}$ in $5 \% \mathrm{CO}_{2}$. The next morning, brain slices were equilibrated for $1 \mathrm{~h}$ in aCSF containing (in $\mathrm{mM}$ ): $126 \mathrm{NaCl}, 2.5 \mathrm{KCl}, 1.25 \mathrm{NaH}_{2} \mathrm{PO}_{4}$, $2 \mathrm{CaCl}_{2}, 1 \mathrm{MgCl}_{2}, 26 \mathrm{NaHCO}_{3}, 2.5$ glucose, and 22.5 sucrose to reduce glucose concentration to a physiological level (Silver and Erecinska, 1994). Slices were then placed into the recording chamber, heated at $\sim 30^{\circ} \mathrm{C}$ and continuously perfused at $1-$ $2 \mathrm{ml} / \mathrm{min}$.

\section{Double-Immunofluorescence Labeling}

Following viral transduction, slices were fixed overnight at $4^{\circ} \mathrm{C}$ in $0.1 \mathrm{M}$ phosphate-buffer containing $4 \%$ formaldehyde. Then, slices were rinsed with phosphate-buffer saline (PBS), permeabilized with $\mathrm{PBS} /$ gelatin $0.2 \% /$ Triton $0.25 \%$, and incubated overnight at $4^{\circ} \mathrm{C}$ with rabbit anti-Satb2 (1:1000, ab34735, Abcam; Lee et al., 2010) and chicken anti-GFP (1:1000, GFP-1020, Aves Labs; Tricoire et al., 2010). After washing in PBS, the respective immunoreactions were visualized with the following secondary antibodies: goat-anti-rabbit AlexaFluor 555 (1:1000, A-21430, Thermo Fisher Scientific) and goat-anti chicken AlexaFluor 488 (1:1000, A-11039, Thermo Fisher Scientific) incubated $1 \mathrm{~h}$ at room temperature. Sections were mounted with fluoromount-G (Southern Biotech) on slides for visualization. Images of immunostained material were acquired using a Leica TCS SP5 AOBS inverted confocal microscope with a $40 \times$ objective $(40 \times$ HCX P APO CS NA 1.25-0.75/Oil) and LAS AF software (Leica Microsystems). Cell counting was performed using Image Pro Analyzer 7.0.0.951 (MediaCybernetics).

\section{FRET Imaging}

Recordings were made from visually identified pyramidal cells in layer II and III of the mouse somatosensory cortex. Widefield fluorescent images were obtained using a double port upright microscope (BX51WI, WI-DPMC Olympus) with a 40x objective (LUMPlan FL N 40×/0.80 W) and a digital camera (CoolSnap HQ2, Roper Scientific or Orca Flash 4.0, Hamamatsu) attached on the front port of the microscope. The glucose sensor FLII ${ }^{12}$ Pglu-700 $\mu \delta 6$ was excited at $400 \mathrm{~nm}$ with a light emitting device (LED; CoolLED, Precise Excite) using Imaging Workbench 6.0.25 software (INDEC BioSystems) and excitation (HC 438/24, Semrock) and dichroic filters (HC BS 458, Semrock). Double fluorescence images were collected every $15 \mathrm{~s}$ by alternating the fluorescence emission filters for the CFP (HC 483/32 Semrock) and the YFP (HC 542/27, Semrock) using a filter wheel (Lambda 10B, Sutter Instruments). In parallel, infrared transmitted light images of slices were continuously monitored on the back-port of the microscope using an infrared collimated LED as a light source (780 nm, Thorlabs), Dodt gradient contrast optics (DGC; Luigs and Neumann; Dodt and Zieglgansberger, 1998), a customized beam splitter (725 DCSPXR, Semrock) and an analogic CCD camera (XC ST-70 CE, Sony). The focal plane was maintained constant on-line using infrared DGC images of cells as anatomical landmarks (Lacroix et al., 2015). To compensate for potential $x-y$ drifts all images were realigned off-line using the "StackReg" plug-in (Thevenaz et al., 1998) of Image 1.48 software. Fluorescence ratios were calculated by dividing the registered YFP images by the registered CFP images using FIJI ${ }^{1}$. On average $8.0 \pm 0.3$ transduced neurons were visualized in the field of view of the CoolSnap HQ2 with no statistical difference between $3 \times \mathrm{Tg}-\mathrm{AD}$ and non-Tg mice $(U(29,30)=390, p=0.5027)$. To determine regions of interests (ROIs) corresponding to the cytosolic part of the soma, nuclei were manually delineated and excluded from somatic ROIs. The mean ratio was measured at each time point using the same ROIs. The experiments lasted more than $30 \mathrm{~min}$, leading to a small drift in the ratio baseline (Figure 2B). The drift was corrected by a linear curve fitting (John et al., 2008) using Clampfit 10.4 software (MDS). Variations of fluorescence ratio were expressed as the ratio ( $\mathrm{R}-\mathrm{R} 0) / \mathrm{R} 0$, where $\mathrm{R}$ corresponds to the fluorescence ratio in the ROI at a given time point, and R0 corresponds to the mean fluorescence ratio in the same ROI during the $10 \mathrm{~min}$ control baseline prior to changes in extracellular glucose concentration or application of drugs. Relative ratio traces were smoothed with a sliding five-point median filter to eliminate sharp artifacts resulting from transient loss of focus.

\section{Whole-Cell Recordings in Acute Slices}

Patch pipettes (4-6 M $\Omega$ ) pulled from borosilicate glass were filled with $8 \mu \mathrm{l}$ of RNAse free internal solution containing in (mM): $144 \mathrm{~K}$-gluconate, $3 \mathrm{MgCl}_{2}, 0.5 \mathrm{EGTA}, 10 \mathrm{HEPES}, \mathrm{pH}$ $7.2(285 / 295 \mathrm{mOsm})$. Whole-cell recordings were performed at $27.0 \pm 0.5^{\circ} \mathrm{C}$ using a patch-clamp amplifier (Axopatch 200B, MDS). Data were filtered at $5-10 \mathrm{kHz}$ and digitized at $50 \mathrm{kHz}$ using an acquisition board (Digidata 1440, MDS) attached to a personal computer running PCLAMP 10.2 software package (MDS). Membrane potential values were corrected for liquid junction potential $(-15.6 \mathrm{mV})$. Resting membrane potential

\footnotetext{
${ }^{1}$ http://fiji.sc/Fiji
} 
of neurons was measured just after passing in whole-cell configuration. Only neurons with a resting membrane potential more negative than $-60 \mathrm{mV}$ were analyzed further. A total of 32 electrophysiological properties chosen to describe the electrophysiological diversity of cortical neurons (Ascoli et al., 2008) were determined as previously described (Karagiannis et al., 2009).

\section{Cytoplasm Harvesting and scRT-PCR}

At the end of the whole-cell recording, lasting $<15 \mathrm{~min}$, the cytoplasmic content was aspirated in the recording pipette. The pipette's content was expelled into a test tube and RT was performed in a final volume of $10 \mu \mathrm{l}$, as described previously (Lambolez et al., 1992). The scRT-PCR protocol was designed to probe simultaneously the expression of neuronal markers and key molecular elements of glucose metabolism. Two-steps amplification was performed essentially as described (Cauli et al., 1997; Devienne et al., 2018). Briefly, cDNAs present in the $10 \mu \mathrm{l}$ reverse transcription reaction were first amplified simultaneously using all external primer pairs listed in Table 1. Taq polymerase (2.5 U; Qiagen) and 20 pmol of each primer were added to the buffer supplied by the manufacturer (final volume, $100 \mu \mathrm{l})$, and 20 cycles $\left(94^{\circ} \mathrm{C}, 30 \mathrm{~s} ; 60^{\circ} \mathrm{C}, 30 \mathrm{~s}\right.$; and $72^{\circ} \mathrm{C}, 35 \mathrm{~s}$ ) of PCR were run. Second rounds of PCR were performed using $1 \mu \mathrm{l}$ of the first PCR product as a template. In this second round, each cDNA was amplified individually using its specific nested primer pair (Table 1) by performing 35 PCR cycles (as described above). A ten $\mu \mathrm{l}$ of each individual PCR product were run on a $2 \%$ agarose gel stained with ethidium bromide using $\Phi$ X174 digested by HaeIII as a molecular weight marker.

\section{Drugs}

Changes in extracellular glucose concentration were compensated by changes in sucrose concentration to maintain the osmolarity of the aCSF constant as previously described (Miki et al., 2001). Iodoacetic acid (IAA) and 6-aminonicotinamide (6-AN) were purchased from Sigma-Aldrich.

\section{Statistical Analyses}

Statistical analyses were performed with Statistica 6 (Statsoft). All values are expressed as mean \pm SEM. Statistical significance of FRET ratio changes and electrophysiological properties of pyramidal cells of 3xTg-AD and non-Tg mice was determined using the Mann-Withney $U$ test. Comparison of the occurrence of the genes expressed by pyramidal cells of the two mice lines was determined using Fisher's exact test. Statistical significance on all figures uses the following convention: ${ }^{*} p<0.05,{ }^{* *} p<0.01$, and $* * * p<0.001$.

TABLE 1 | PCR primers.

\begin{tabular}{|c|c|c|c|c|}
\hline Genes Accession \# & First PCR primers & Size (bp) & Second PCR nested primers & Size (bp) \\
\hline vGluT1 & Sense, -113: GGCTCCTIITCTGGGGCTAC & 259 & Sense, -54: ATTCGCAGCCAACAGGGTCT & 153 \\
\hline NM_182993 & Antisense, 126: CCAGCCGACTCCGTTCTAAG & & Antisense, 79: TGGCAAGCAGGGTATGTGAC & \\
\hline GAD65 & Sense, 99: CCAAAAGTTCACGGGCGG & 375 & Sense, 219: CACCTGCGACCAAAAACCCT & 248 \\
\hline NM_008078 & Antisense, 454: TCСTCCAGATTTGCGGTTG & & Antisense, 447: GATाTGCGGTTGGTCTGCC & \\
\hline GAD67 & Sense, 529: TACGGGGTTCGCACAGGTC & 598 & Sense, 801: CCCAGAAGTGAAGACAAAAGGC & 255 \\
\hline NM_008077 & Antisense, 1,109: CCCAGGCAGCATCCACAT & & Antisense, 1,034: AATGCTCCGTAAACAGTCGTGC & \\
\hline GluT1 & Sense, 5: ATCCCAGCAGCAAGAAGGTGA & 333 & Sense, 88: ACTGGTGTCATCAACGCCCC & 164 \\
\hline NM_011400 & Antisense, 317: AGAAGCCCATAAGCACAGCAG & & Antisense, 230: CCGACAGAGAAGGAACCAATCA & \\
\hline GluT3 & Sense, 1: ATGGGGACAACGAAGGTGAC & 358 & Sense, 23: CATCTCTGGTGTTCGCCGT & 310 \\
\hline NM_011401 & Antisense, 336: GCATTTCAACAGACTCCGCTATC & & Antisense, 314: GCGAATCCCATAAGGCAGC & \\
\hline HK1 & Sense, 879: CGAGAAGATGGTGAGCGGC & 472 & Sense, 986: TCACGAGGGGCAAGTTCACC & 330 \\
\hline NM_001146100 & Antisense, 1,333: GCCACTGCCACTCTCCGA & & Antisense, 1,298: CCGAGTCAGGCACCAGGC & \\
\hline Pfkfb3 & Sense, 211: GTGGGAGAGTATCGGCGTGA & 494 & Sense, 255: CAACTTCTTCCGCCCTGACA & 365 \\
\hline NM_001177752 & Antisense, 685: ATTCGGCTCTGGATGTGGTC & & Antisense, 596: CACATITATCAGGGTCAAGAGGCT & \\
\hline PFK1m & Sense, 49: GCCATCGCCGTGTTGACC & 247 & Sense, 106: GCTGTGGTCCGAGTTGGTATCT & 160 \\
\hline NM_001163487 & Antisense, 276: GTCGTCCTTCTCGCTCTCGG & & Antisense, 246: ATCGGGCACTTCCAATCACT & \\
\hline PFK11 & Sense, 180: AGGAGGCGAGAACATCAAGC & 408 & Sense, 304: GCCTACAATCTGCTCCAACACG & 169 \\
\hline NM_008826 & Antisense, 568: GCAGTGGTAGTGATGGCGTC & & Antisense, 451: TGGTCAAGTGTGCGTAGTTCTG & \\
\hline PFK1p & Sense, 409: CGAAAGGAGTGGAGCGGA & 306 & Sense, 438: GCTGGCTCGGAATGGTGAT & 219 \\
\hline NM_019703 & Antisense, 696: AAGGAACACCCAGTCGGCA & & Antisense, 637: TGTCTCCCCATCACCTCCAG & \\
\hline G6PDx & Sense, 206: GCTATGCCCGCTCACGAC & 303 & Sense, 491: CCACGATGATGCGGTTCC & 143 \\
\hline NM_008062 & Antisense, 232: GACGACATCCGAAAGCAGAGTG & & Antisense, 353: ATGTGGCTGTTGAGGTGCTTAT & \\
\hline Gys1 & Sense, 3: GCCTCTCAGCCGCAGTCT & 313 & Sense, 66: CGACCCCGAGAACGCAGT & 157 \\
\hline NM_030678 & Antisense, 294: ACGCCCAAAATACACCTTACAA & & Antisense, 205: CCTCACACCCTGCTCCGT & \\
\hline PygB & Sense, 108: GCATTCACGCTGGTCAAGG & 292 & Sense, 156: CTTCTTCGCTCTGGCACACA & 110 \\
\hline NM_153781 & Antisense, 380: CCCAAGACCAGCATCCTCCT & & Antisense, 244: CCAGGGAAAGGTAATAGATGCG & \\
\hline
\end{tabular}

Position 1, first base of the start codon. 


\section{RESULTS}

\section{Glucose Uptake}

We used a recombinant Sindbis virus (see Materials and Methods) to express the FRET glucose sensor FLII ${ }^{12}$ Pglu$700 \mu \delta 6$ (Takanaga et al., 2008) in neurons of neocortical slices. Expression of the biosensor was preferentially observed in pyramidal shaped cells of layers II and III (Figures 1, 2A), consistent with previous reports (Drobac et al., 2010; Hu et al., 2011). The sensor was observed both in somata and in proximal dendrites, but virtually absent from nuclei (Figures 1, 2A). The pyramidal identity of transduced cells was next examined by double immunofluorescence for GFP and Satb2, a pyramidal cells transcription factor (Britanova et al., 2008; Lee et al., 2010; Lacroix et al., 2015). A large majority of transduced cells displayed a nucleus positive for Satb2 $(75.1 \pm 3.1 \%, n=415$ GFP-expressing cells from three different mice) confirming the pyramidal tropism of the Sindbis virus (Chen et al., 2000; Lendvai et al., 2000; Furuta et al., 2001; Drobac et al., 2010). Optical recordings were then performed in layer II and III by measuring the YFP/CFP emission ratio of the biosensor in the cytosol.

The resting intracellular glucose concentration is determined by glucose transport (uptake and efflux) and metabolism (Bittner C.X. et al., 2010; Hou et al., 2011). We first evaluated the capability of supragranular neuron to take-up glucose by monitoring dynamic changes in intracellular glucose during an increase in extracellular glucose concentration (John et al., 2008; Takanaga et al., 2008; Hou et al., 2011). Increasing extracellular glucose from $2.5 \mathrm{mM}$, a physiologically relevant glucose concentration (Silver and Erecinska, 1994), to $10 \mathrm{mM}$, a glucose concentration nearly saturating the sensor (Takanaga et al., 2008) and classically used in brain slices experiments, lead to a slowly developing increase in fluorescence emission

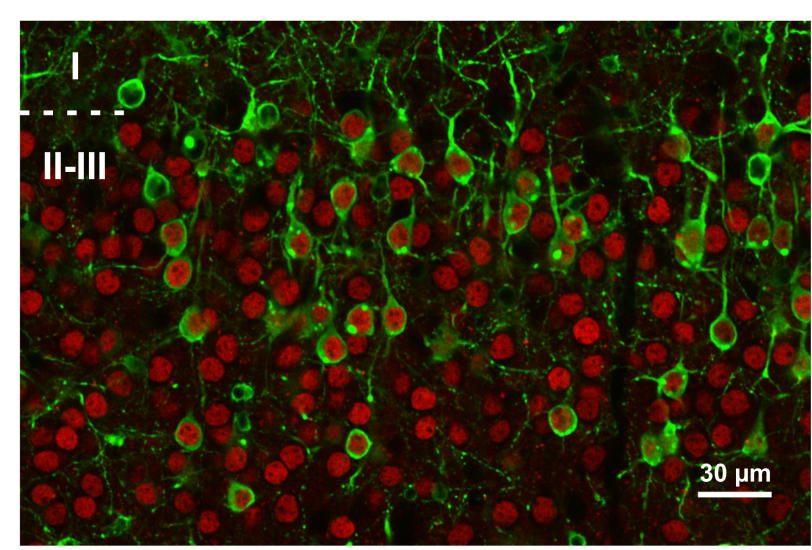

FIGURE 1 | Expression of the FRET glucose sensor in neocortical slices. Representative single plane confocal image of a slice expressing the FLII12Pglu-700 $\mu \delta 6$ biosensor following sindbis viral transduction. Cells expressing the FRET glucose sensor are identified by their GFP fluorescence (green). Pyramidal cells are immunolabeled for the Satb2 transcription factor (red). Dashed line represents layer I and II border. Note that most layer II and III transduced cells are stab2 positive. ratio (Figures $2 \mathrm{~B}, \mathrm{C}$ ). This confirms that pyramidal neurons from juvenile mice of both genotypes have the capability to take up glucose (Diaz-Garcia et al., 2017).

During application of $10 \mathrm{mM}$ glucose the relative increase in fluorescence ratio was $3.8 \pm 0.3 \%$ in non-Tg neurons vs. $3.2 \pm 0.3 \%$ in $3 \times \mathrm{Tg}-\mathrm{AD}$ neurons after $10 \mathrm{~min}[U(74,57)=1,787$, $p=0.1359], 5.9 \pm 0.4 \%$ vs. $5.6 \pm 0.6 \%[U(74,57)=1,844$, $p=0.2203]$ after $20 \mathrm{~min}, 7.4 \pm 0.5 \%$ vs. $6.9 \pm 0.7 \%$ $[U(74,57)=1,822, p=0.1841]$ after $30 \mathrm{~min}, 8.8 \pm 0.6 \%$ vs. $8.4 \pm 0.9 \%[U(74,57)=1,843, p=0.2185]$ after $40 \mathrm{~min}$ and $10.2 \pm 0.7 \%$ vs. $9.4 \pm 1.1 \%$ after $[U(74,57)=1,785$, $p=0.1335]$ after $50 \mathrm{~min}$. These results revealed that the glucose accumulations were very similar between pyramidal cells of juvenile non-Tg and 3xTg-AD mice (Figure 2C). Since in slices we cannot estimate the resting intracellular glucose concentration, we next thought to determine whether the elimination rate of glucose was similar. To do so, we reduced extracellular glucose concentration close to 0 (Bittner C.X. et al., 2010).

\section{Glucose Metabolic Activity}

Decreasing extracellular glucose from 2.5 to $0.2 \mathrm{mM}$ led to a marked drop in relative fluorescence ratio (Figure $\mathbf{3 A}$ ). This indicates that pyramidal cells metabolize glucose under resting condition as recently reported (Diaz-Garcia et al., 2017). The slopes of intracellular glucose decrease, measured between 2 and $7 \mathrm{~min}$ after glucose restriction, were not statistically different between non-Tg and 3xTg-AD pyramidal cells $[-2.0 \pm 0.0 \%$ $\min ^{-1}$ vs. $\left.-2.2 \pm 0.1 \% \min ^{-1}, U(65,88)=2,666, p=0.4740\right]$. This indicates that the elimination rates of glucose, which depend on both efflux and metabolism, were similar. Taken together, the similar accumulation and elimination rates we observed (Figures 2, 3) revealed that the capabilities of glucose transport are comparable between non-Tg and 3xTg-AD pyramidal cells.

Nonetheless, scrutinization of the dynamics of intracellular glucose revealed subtle differences between the metabolic activity of pyramidal cells of juvenile non-Tg and 3xTg$\mathrm{AD}$ mice (Figure 3A). After $5 \mathrm{~min}$ of extracellular glucose restriction, the drop was stronger in non-Tg than in $3 \mathrm{xTg}$ $\mathrm{AD}$ mice $[-6.8 \pm 0.4 \%$ vs. $-5.5 \pm 0.3 \%, U(65,88)=2,087$, $p=0.0043$ ] indicating a higher metabolic activity in non$\mathrm{Tg}$ mice at an early stage of glucose restriction (Figure 3 ). However it did not differ after $10 \mathrm{~min}$ of glucose restriction $[-15.2 \pm 0.3 \%$ vs. $-16.1 \pm 0.4 \%, U(65,88)=2,444, p=0.1247$, Figure 3B]. Interestingly, longer glucose restrictions disclosed a higher elimination rate of glucose in 3xTg-AD pyramidal cells (Figure 3), which was evident after $15 \mathrm{~min}[-19.0 \pm 0.3 \%$ vs. $-20.3 \pm 0.4 \%, U(65,88)=2,029, p=0.0022]$ and persisted after $20 \min [-20.8 \pm 0.4 \%$ vs. $-21.9 \pm 0.5 \%, U(65,88)=2,237$, $p=0.0215$, Figure 3B]. The lower and higher glucose elimination rates, respectively observed at early and late stages of glucose depletion in 3xTg-AD pyramidal cells, may suggest that at least two glucose pathways with different kinetics are altered. The similar elimination rates we observed indicate that these alterations roughly counterbalance each other.

To evaluate the relative contribution of different glucose pathways to the metabolic activity of pyramidal cells, we 

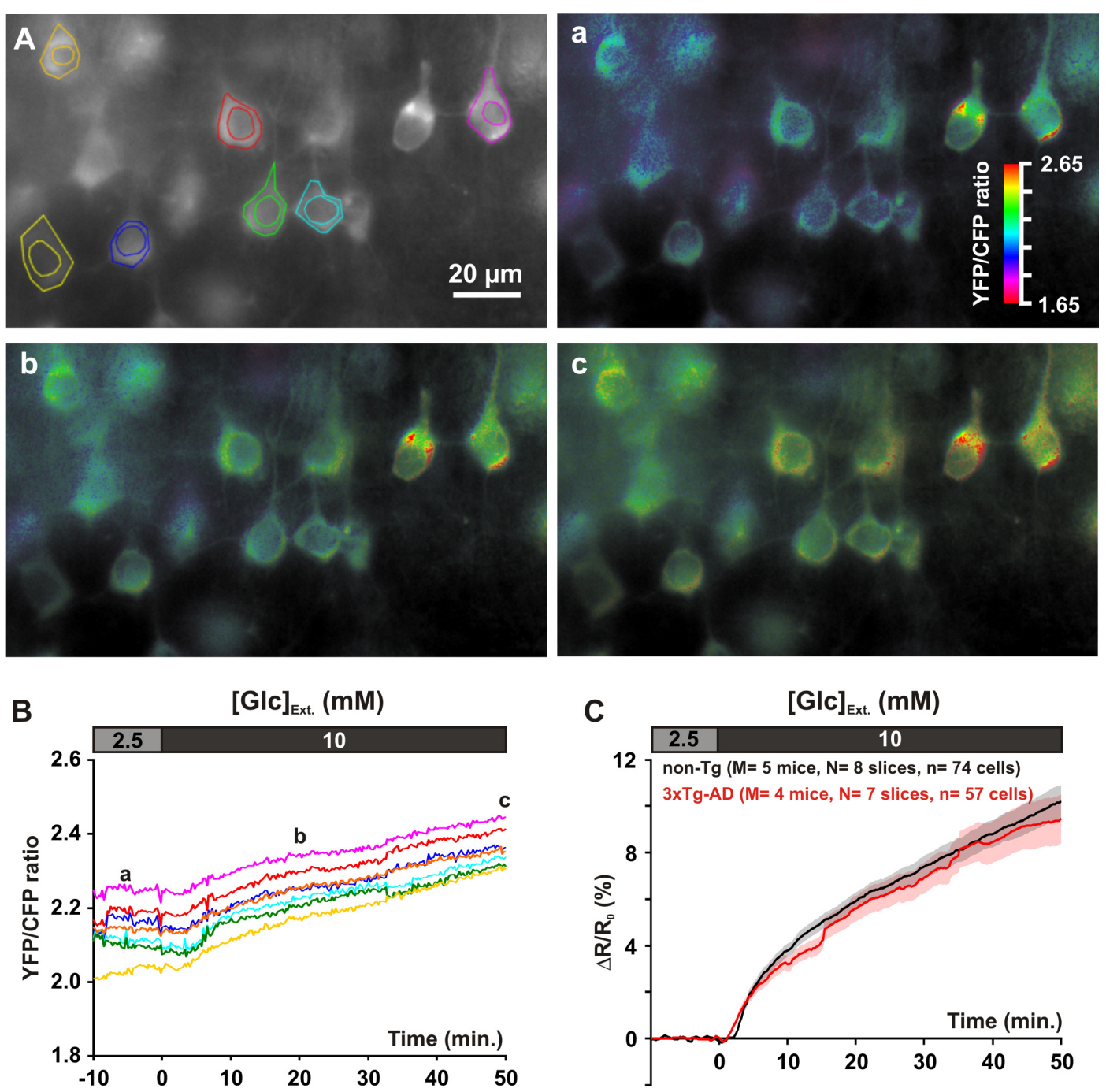

FIGURE 2 | Glucose uptake in layer II and III pyramidal cells. (A) The gray scale image shows the YFP fluorescence. Pseudocolor images show the YFP/CFP ratio value [coded by pixel hue, see scale bar in (a)] and the fluorescence intensity (coded by pixel intensity) at different time points before (a) and after (b,c) superfusion of $10 \mathrm{mM}$ glucose. (B) Traces show average YFP/CFP ratio measure at the cytosolic part of the soma of individual pyramidal cells delineated in (A). (a-c) indicate time points corresponding to the pseudocolor images shown in (A). (C) Mean relative YFP/CFP ratio changes in pyramidal cells of non-Tg (black trace) and 3xTg-AD mice (red trace) induced by superfusion of $10 \mathrm{mM}$ glucose. Traces show mean (solid lines) \pm standard errors of the mean (color shades). Note the slowly developing increase in mean relative ratio during $10 \mathrm{mM}$ glucose superfusion and the similar temporal profiles between non-Tg and 3xTg-AD mice.

monitored glucose accumulation induced by different metabolic inhibitors. We first inhibited glycolysis using IAA, a widely used glyceraldehyde-3-phosphate dehydrogenase (G3PDH) inhibitor that does not interfere with the FRET glucose sensors (John et al., 2008; Bittner C.X. et al., 2010). We used $200 \mu \mathrm{M}$ IAA, a concentration that efficiently inhibits glycolysis in brain slices (Yang et al., 1999; Gordon et al., 2008) with modest impact on the pentose phosphate pathway or lactate dehydrogenase activity (Sabri and Ochs, 1971; Schmidt and Dringen, 2009). Bath application of IAA induced a delayed increase in relative fluorescence ratio in non-Tg pyramidal cells (Figure 4A1), indicative of glucose accumulation and consistent with glycolytic activity in cortical neurons under resting condition (Bittner C.X. et al., 2010; Diaz-Garcia et al., 2017).
Surprisingly, in pyramidal cells of $3 x \mathrm{Tg}-\mathrm{AD}$ mice IAA led to a biphasic response consisting in a transient decrease in intracellular glucose followed by a latter increase (Figure 4A1). The transient decrease, absent in pyramidal cells of non$\mathrm{Tg}$ mice, was observable after $10 \mathrm{~min}$ of IAA application $\left[0.7 \pm 0.2 \%\right.$ vs. $-0.7 \pm 0.6 \%, U(81,34)=569, p=2.480 \times 10^{-7}$, Figure 4A2] and lasted for about $10 \mathrm{~min}$. At that time of glycolysis inhibition, the intracellular glucose dynamics of non-Tg and 3xTg-AD pyramidal cells crossed (Figure 4A1) and did not differ significantly $[0.2 \pm 0.5 \%$ vs. $1.8 \pm 1.4 \%$, $U(81,34)=1,341, p=0.8286$, Figure 4A2]. This transient decrease in glucose level observed under glycolysis inhibition suggests that another glucose-consuming metabolic pathway was stimulated or at least disclosed. A longer exposure to 

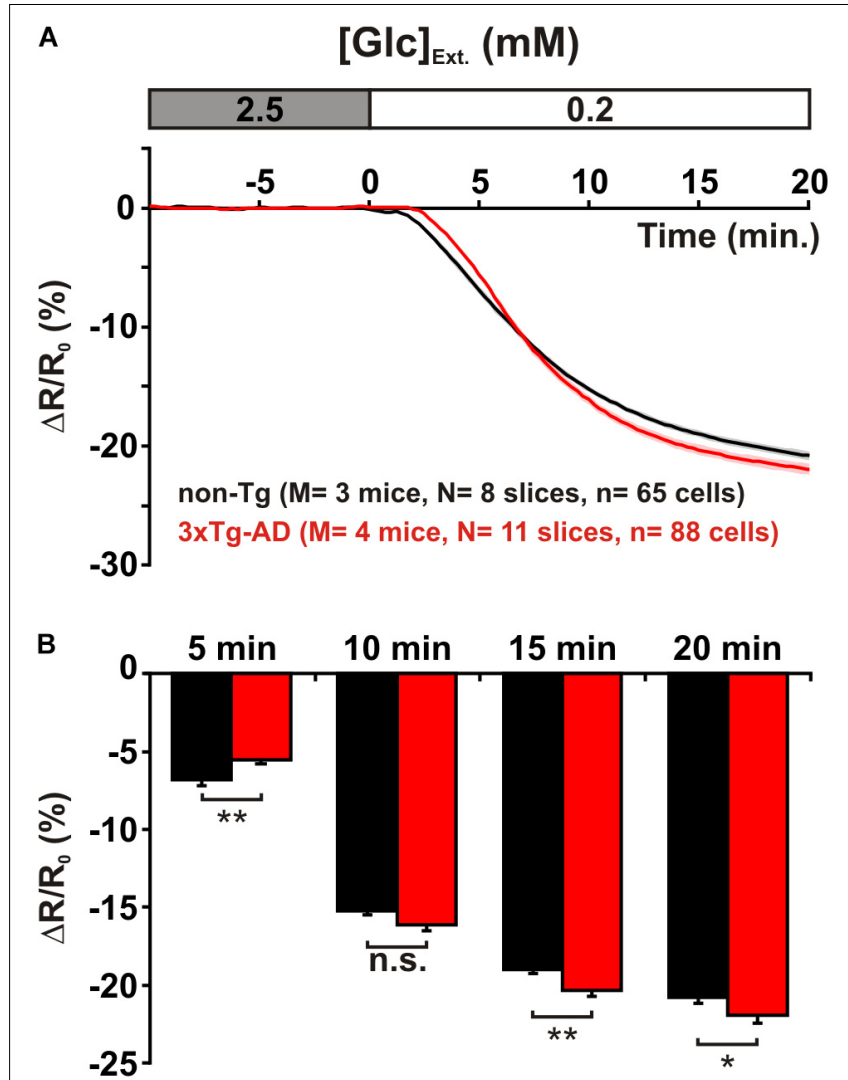

FIGURE 3 | Metabolic activity of layer II and III pyramidal cells. (A) Mean relative YFP/CFP ratio changes in pyramidal cells of non-Tg (black trace) and 3XTg-AD mice (red trace) induced by glucose (Glc) restriction ( $0.2 \mathrm{mM})$. Traces show mean (solid lines) \pm standard errors of the mean (color shades). Note the slowly developing decrease in mean relative ratio during $0.2 \mathrm{mM}$ Glucose superfusion. Note also the difference in the temporal profiles between non-Tg and 3xTg-AD mice. (B) Histograms show the metabolic activity (decrease in relative YFP/CFP ratio) at different time of glucose restriction. After $5 \mathrm{~min}$ of glucose restriction pyramidal cells of non-Tg mice exhibit a higher metabolic activity than those of 3xTg-AD mice. In contrast, during longer glucose restriction pyramidal cells of 3xTg-AD mice display a higher metabolic activity. n.s. not statistically significant.

IAA revealed a higher intracellular glucose increase in $3 \times \mathrm{Tg}$ $\mathrm{AD}$ neurons $[7.0 \pm 0.8 \%$ vs. $14.4 \pm 1.7 \%, U(81,34)=636$, $p=2.715 \times 10^{-6}$ at $\left.30 \mathrm{~min}\right]$. These observations suggest that the glycolysis rate is higher in $3 \mathrm{xTg}-\mathrm{AD}$ than in non-Tg pyramidal cells.

We next evaluated the importance of the pentose phosphate shunt in the metabolism of pyramidal cells and thought to determine whether it is altered in $3 x T g-A D$ pyramidal cells. Applying 6-AN induced a slowly developing increase in intracellular glucose concentration in non-Tg pyramidal cells (Figure 4B1). After $30 \mathrm{~min}$ the amplitude of this increase reached a level comparable to the one observed under glycolysis inhibition (Figures 4A1, B1), indicating that both pathways contribute to the resting glucose metabolism of pyramidal cells.

In contrast, in 3xTg-AD neurons 6-AN induced a slight and transient decrease in intracellular glucose observable after $10 \mathrm{~min}$ $\left[1.7 \pm 0.3 \%\right.$ vs. $\left.-0.4 \pm 0.3 \%, U(78,58)=1,120, p=2.393 \times 10^{-7}\right]$ followed by a very mild increase at $20 \mathrm{~min}[2.9 \pm 0.5 \%$ vs. $\left.0.3 \pm 0.4 \%, U(78,58)=1,365, p=6.195 \times 10^{-5}\right]$ and $30 \mathrm{~min}$ of exposure $[4.7 \pm 0.8 \%$ vs. $0.9 \pm 0.6 \%, U(78,58)=1,389$, $p=9.861 \times 10^{-5}$, Figure 4B2], respectively. These results reveal that the pentose phosphate pathway is dramatically hampered in 3xTg-AD neurons.

In order to investigate further the metabolic pathway disinhibited in 3xTg-AD neurons during glycolysis inhibition, we simultaneously applied IAA and 6-AN to inhibit both glycolysis and the pentose phosphate pathway. Such a combined inhibition induced a biphasic response in both non-Tg and 3xTg-AD pyramidal cells consisting in a small and transient decrease in intracellular glucose followed by a later increase (Figure 4C1). However, the initial dip in intracellular glucose was much stronger and longer lasting in 3xTg-AD neurons (Figure 4C1). Indeed, it was comparable after $10 \mathrm{~min}$ of combined inhibition $[-0.3 \pm 0.2 \%$ vs. $-0.6 \pm 0.3 \%, U(76,43)=1,479, p=0.3943]$ and was particularly marked after $20 \mathrm{~min}[-1.3 \pm 0.4 \%$ vs. $-3.3 \pm 0.7 \%, U(76,43)=1,228, p=0.0245$, Figure 4C2]. Since this transient glucose consumption in $3 \mathrm{xTg}-\mathrm{AD}$ neurons was observed under both glycolysis (Figure 4A1) and combined inhibition (Figure 4C1) and barely during inhibition of the pentose phosphate pathway alone (Figure 4B1), it indicates that glycolysis inhibition is required to disclose the initial dip. It also suggests that the pentose phosphate pathway does not chiefly underlay this transient glucose consumption. A longer combined inhibition resulted in an intracellular glucose increase that was higher in non-Tg than in 3xTg-AD pyramidal cells [10.2 $\pm 0.7 \%$ vs. $7.1 \pm 1.0 \%, U(76,43)=1,267, p=0.0423$, Figures 4C1, C2] These observations suggest that the lower pentose phosphate activity observed in 3xTg-AD (Figure 4A) neurons is partially compensated by a higher glycolytic activity (Figures 4B,C).

\section{Molecular Characterization of Layer II and III Pyramidal Cells}

To determine the main genes of glucose metabolism underlying the metabolic program of pyramidal cells and to evaluate whether transcriptomic modifications could mediate the alterations observed in 3xTg-AD mice, we analyzed the expression profiles of these genes in non-Tg and $3 \mathrm{xTg}-\mathrm{AD}$ pyramidal cells by single cell RT-multiplex PCR (scRT-mPCR). The protocol was designed to probe the expression of vGluT1 and GAD65 and 67, taken as glutamatergic and GABAergic markers, respectively. The key genes of glucose metabolism included two glucose transporters GluT1 and GluT3, the hexokinase isoform HK1, the main brain phosphofructokinase-2 isoform; Pfkfb3, the muscle, liver and platelet isoforms of phosphofructokinase-1 (PFK1m, 1 and $\mathrm{p}$ ), the rate limiting enzyme of the pentose phosphate pathway (glucose-6-phosphate dehydrogenase, G6PDx), as well as glycogen synthase and phosphorylase isoforms Gys1 and PygB. The reliability of the scRT-mPCR was tested on $1 \mathrm{ng}$ of total RNA purified from mouse whole brain. As expected, all PCR generated fragments had the sizes predicted by their mRNA sequences (Figure 5 and Table 1) confirming the sensitivity of the amplification procedure (Cauli et al., 1997). 

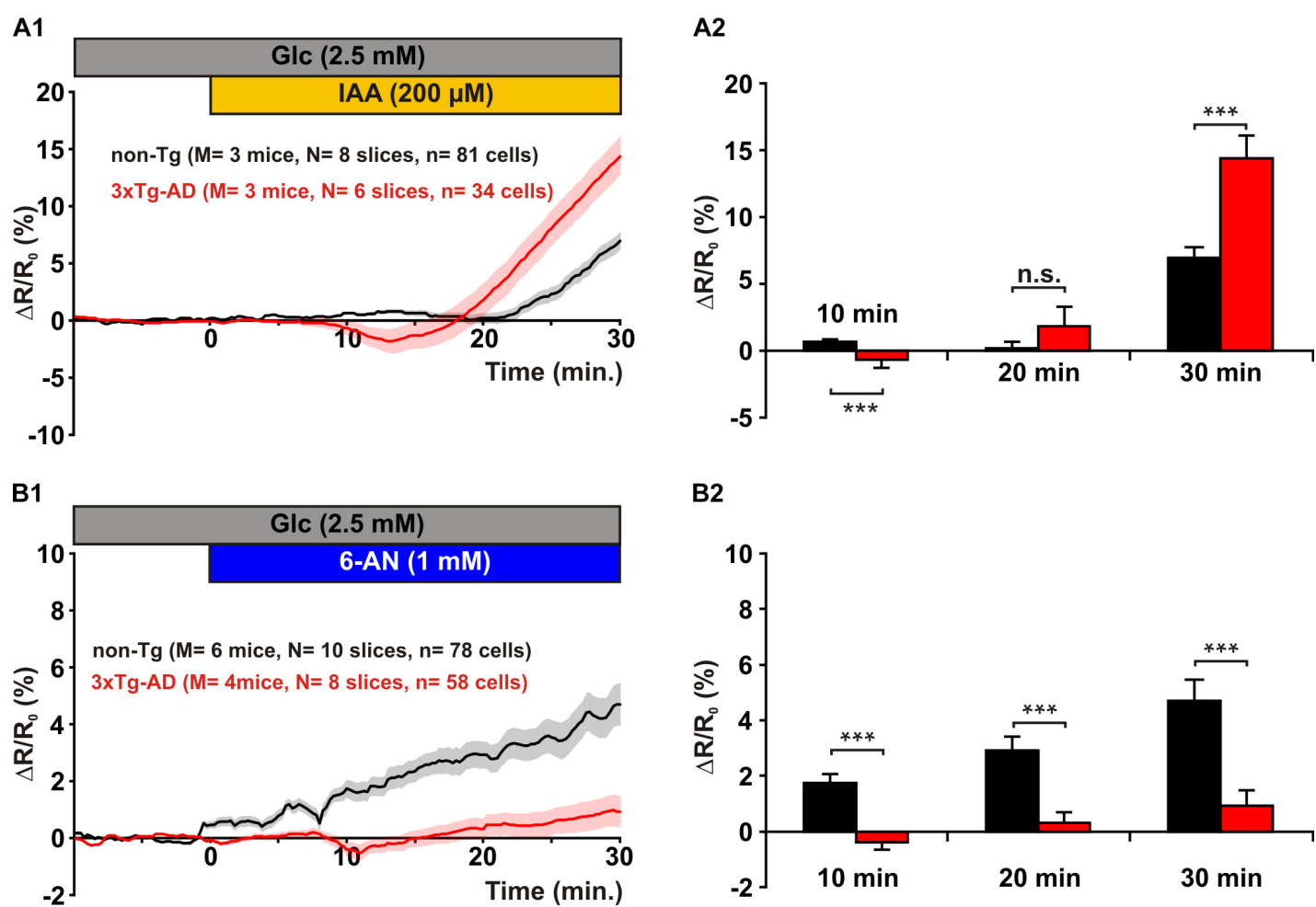

B2
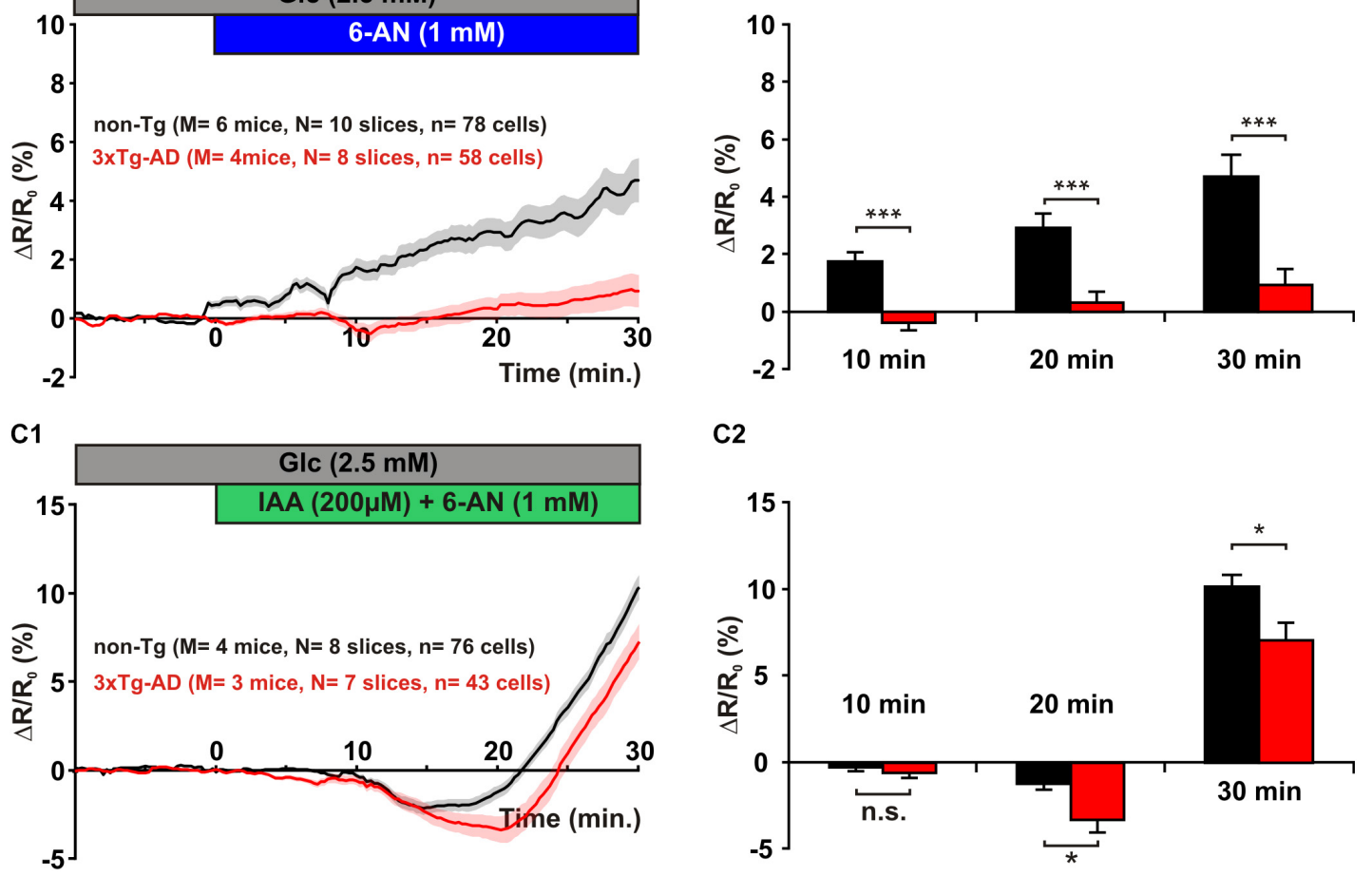

FIGURE 4 | Glucose metabolic pathways in layer II and III pyramidal cells. Left panels show the mean relative YFP/CFP ratio changes in pyramidal cells of non-Tg (black traces) and 3xTg-AD mice (red traces) induced by glycolysis inhibition with IAA (A1), pentose phosphate pathway inhibition with 6-AN (B1), and combined inhibition with both IAA and 6-AN (C1). Traces show mean (solid lines) \pm standard errors of the mean (color shades). Histograms show the metabolic activity (decrease in relative YFP/CFP ratio) at different time of glycolysis inhibition (A2), pentose phosphate pathway inhibition (B2), and combined inhibition (C2). n.s. not statistically significant. (A1) Note the delayed increase in mean relative ratio in non-Tg pyramidal cells during IAA application. Note also the early decrease followed by a late increase in pyramidal cells of 3xTg-AD mice. (A2) After 10 min of IAA application pyramidal cells of 3xTg-AD mice develop a transient increase in metabolic activity. Longer application reveals a larger impact of glycolysis inhibition in pyramidal cells of 3xTg-AD mice than in pyramidal cells of non-Tg mice. (B1) Note the very low increase in mean relative ratio during 6-AN application in pyramidal cells of 3XTg-AD mice. (B2) The mean increase in relative ratio is higher in pyramidal cells of non-Tg mice at 10, 20, and 30 min of 6-AN superfusion. (C1) Note the transient decrease in mean relative ratio during combined IAA and 6-AN application more pronounced in pyramidal cells of 3xTg-AD mice than in non-Tg neurons. (C2) After 20 min of combined inhibition pyramidal cells of 3xTg-AD mice exhibit a marked transient increase in metabolic activity. Longer application reveals an accumulation of glucose smaller in pyramidal cells from 3xTg-AD than from non-Tg mice.

Layer II and III pyramidal cells were first visually identified on the basis of the triangular shape of their soma and by the presence of a prominent apical dendrite. Pyramidal cells typically fired long duration action potentials with a pronounced frequency adaptation (Figure 6A and Tables 2-5) characteristic of Regular Spiking neurons (McCormick et al., 1985; Cauli et al., 1997; Karagiannis et al., 2009;
Lacroix et al., 2015). We did not observe any difference between the electrophysiological properties of non-Tg and 3xTg-AD juvenile pyramidal cells (Tables 2-5), consistent with previous reports (Yamamoto et al., 2011 ). Their glutamatergic phenotype was further confirmed by the detection of vGluT1 mRNAs and the absence of GAD65 and GAD67 transcripts (Figures 6B,C). 


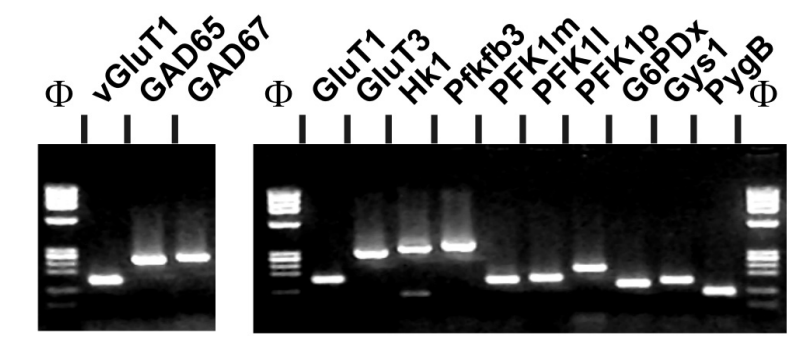

FIGURE $\mathbf{5}$ | Sensitivity of the RT-mPCR. Total whole brain RNAs (1 ng) were subjected to a RT-PCR protocol. The PCR products were resolved in separate lanes by agarose gel electrophoresis in parallel with $\Phi \times 174$ digested by Haell as molecular marker and stained with ethidium bromide. The amplified fragments correspond to neuronal markers (left), glucose transporters and key enzymes of glucose metabolic pathways (right).

GluT1 and GluT3 mRNAs were respectively detected in 29\% ( $n=9$ of 31 cells) and $48 \%$ ( $n=15$ of 31 cells) in non-Tg neurons and in $18 \%(n=5$ of 28 cells, $p=0.3703)$ and $21 \%(n=6$ of 28 cells, $p=0.0555$ ) in 3xTg-AD neurons (Figures 6B,C). GluT1 and GluT3 transcripts were rarely co-detected in both non-Tg $(23 \%$, $n=7$ of 31 cells) and $3 \times$ Tg-AD neurons ( $4 \%, n=1$ of 28 cells, $p=0.0547)$. Similar proportions of neurons were found to express only GluT1 or only GluT3 in non-Tg and 3xTg-AD neurons (7\%, $n=2$ of 31 cells vs. $14 \%, n=4$ of 28 cells, $p=0.4092$ for GluT1 and $26 \%, n=8$ of 31 cells vs. $18 \%, n=5$ of 28 cells, $p=0.5398$ for GluT3, respectively). Finally, we detected at least one of these two GluTs in a similar proportion of non- $\operatorname{Tg}(55 \%, n=17$ of 31 cells) and 3xTg-AD neurons (36\%, $n=10$ of 28 cells, $p=0.1925)$. These observations are consistent with the similar glucose uptake capacity that we observed in non-Tg and 3xTg-AD layer II and III pyramidal cells (Figure 2).

Similarly, the frequency of detection of HK1 was not different between non-Tg (42\%, $n=13$ of 31 cells) and $3 \times \mathrm{Tg}$ neurons

TABLE 2 | Subthreshold properties of pyramidal cells.

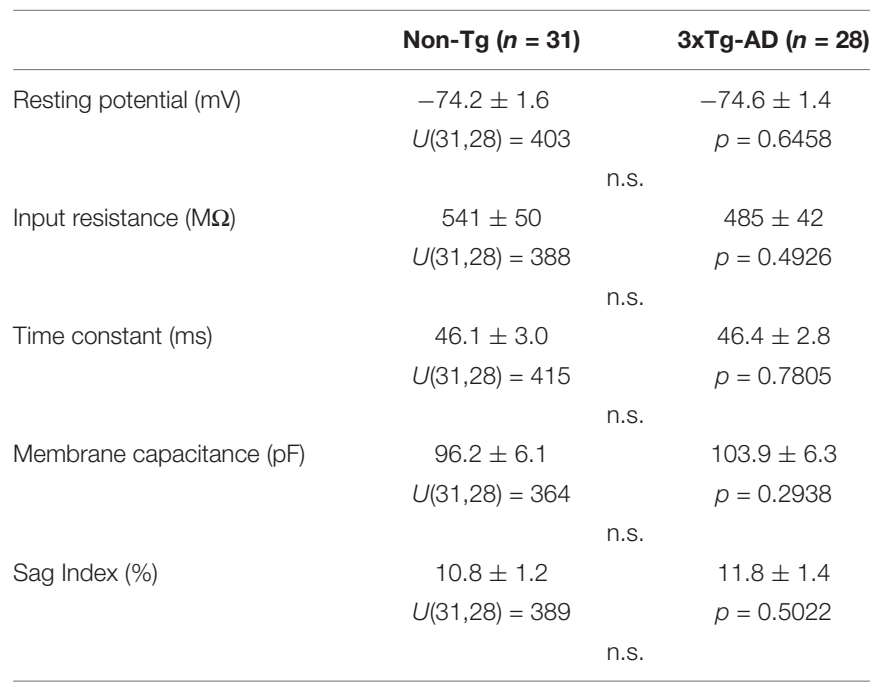

n, number of cells; n.s., not statistically significant.

Mann-Whitney $U$ tests and corresponding exact $p$ values.
(54\%, $n=15$ of 28 cells, $p=0.4390)$. Pfkfb3 was only detected in a minority of pyramidal cells of non- Tg (13\%, $n=4$ of 31 cells) and $3 \times$ Tg-AD $(4 \%, n=1$ of 28 cells, $p=0.3563$, Figures $6 B, C)$. The most frequently detected phosphofructokinase- 1 isoforms in both non-Tg and 3xTg-AD neurons were PFK1m $(84 \%, n=26$ of 31 cells and $64 \%, n=18$ of 28 cells, $p=0.1339$, Figures $6 B, C)$ and PFK1p (58\%, $n=18$ of 31 cells, and $50 \%, n=14$ of 28 cells, $p=0.3598$, Figures 6B,C). PFK11 was observed in 36\% $(n=11$ of 31 cells) and $29 \%$ ( $n=8$ of 28 cells, $p=0.3874$, Figures $6 B, C)$ in non-Tg and 3xTg-AD neurons, respectively.

G6PDx was detected in $16 \%(n=5$ of 31 cells $)$ and $18 \%$ ( $n=5$ of 28 cells) of the non-Tg and $3 \times$ Tg-AD pyramidal cells, respectively ( $p=1.000$, Figures $6 \mathbf{B}, \mathbf{C})$. The glycogen synthase Gys1 was never detected in non-Tg neurons and rarely in 3xTgAD neurons (7\%, $n=2$ out of $28, p=0.2209$, Figures $6 B, C)$. Finally, the glycogen phosphorylase, PygB was observed in

TABLE 3 | Just above threshold properties of pyramidal cells.

\begin{tabular}{|c|c|c|}
\hline & Non-Tg $(n=31)$ & $3 \times T g-A D(n=28)$ \\
\hline \multirow[t]{3}{*}{ Rheobase (pA) } & $17.2 \pm 4.4$ & $18.1 \pm 6.9$ \\
\hline & $U(31,28)=426$ & $p=0.9101$ \\
\hline & \multicolumn{2}{|c|}{ n.s. } \\
\hline \multirow[t]{3}{*}{ First spike latency (ms) } & $274.0 \pm 24.4$ & $248.9 \pm 23.2$ \\
\hline & $U(31,28)=376$ & $p=0.3855$ \\
\hline & \multicolumn{2}{|c|}{ n.s. } \\
\hline \multirow[t]{3}{*}{ Adaptation (Hz/s) } & $-1.7 \pm 1.2$ & $-0.6 \pm 0.4$ \\
\hline & $U(31,28)=421$ & $p=0.8506$ \\
\hline & \multicolumn{2}{|c|}{ n.s. } \\
\hline \multirow[t]{3}{*}{ Minimal steady state frequency $(\mathrm{Hz})$} & $5.2 \pm 0.4$ & $4.5 \pm 0.3$ \\
\hline & $U(31,28)=389$ & $p=0.5022$ \\
\hline & \multicolumn{2}{|c|}{ n.s. } \\
\hline
\end{tabular}

n, number of cells; n.s., not statistically significant. Mann-Whitney $U$ tests and corresponding exact $p$ values.

TABLE 4 | Firing properties of pyramidal cells.

\begin{tabular}{|c|c|c|}
\hline & Non-Tg $(n=31)$ & $3 \times \operatorname{Tg}-\mathrm{AD}(n=28)$ \\
\hline \multirow[t]{3}{*}{ Amplitude accommodation (mV) } & $5.6 \pm 1.2$ & $6.8 \pm 1.0$ \\
\hline & $U(31,28)=321$ & $p=0.0878$ \\
\hline & \multicolumn{2}{|c|}{ n.s. } \\
\hline \multirow[t]{3}{*}{ Amplitude of early adaptation $(\mathrm{Hz})$} & $42.1 \pm 4.1$ & $50.2 \pm 4.2$ \\
\hline & $U(31,28)=334$ & $p=0.1317$ \\
\hline & \multicolumn{2}{|c|}{ n.s. } \\
\hline \multirow[t]{3}{*}{ Time constant of early adaptation (ms) } & $24.2 \pm 1.5$ & $22.7 \pm 1.5$ \\
\hline & $U(31,28)=372$ & $p=0.3532$ \\
\hline & \multicolumn{2}{|c|}{ n.s. } \\
\hline \multirow[t]{3}{*}{ Maximal steady-state frequency $(\mathrm{Hz})$} & $29.3 \pm 1.2$ & $31.8 \pm 1.6$ \\
\hline & $U(31,28)=333$ & $p=0.1278$ \\
\hline & \multicolumn{2}{|c|}{ n.s. } \\
\hline \multirow[t]{2}{*}{ Late adaptation ( $\mathrm{Hz} / \mathrm{s})$} & $-12.8 \pm 0.8$ & $-12.2 \pm 0.7$ \\
\hline & $U(31,28)=412$ & $p=0.7460$ \\
\hline
\end{tabular}

n, number of cells; n.s., not statistically significant. Mann-Whitney $U$ tests and corresponding exact $p$ values. 
TABLE 5 | Action potential waveforms of pyramidal cells.

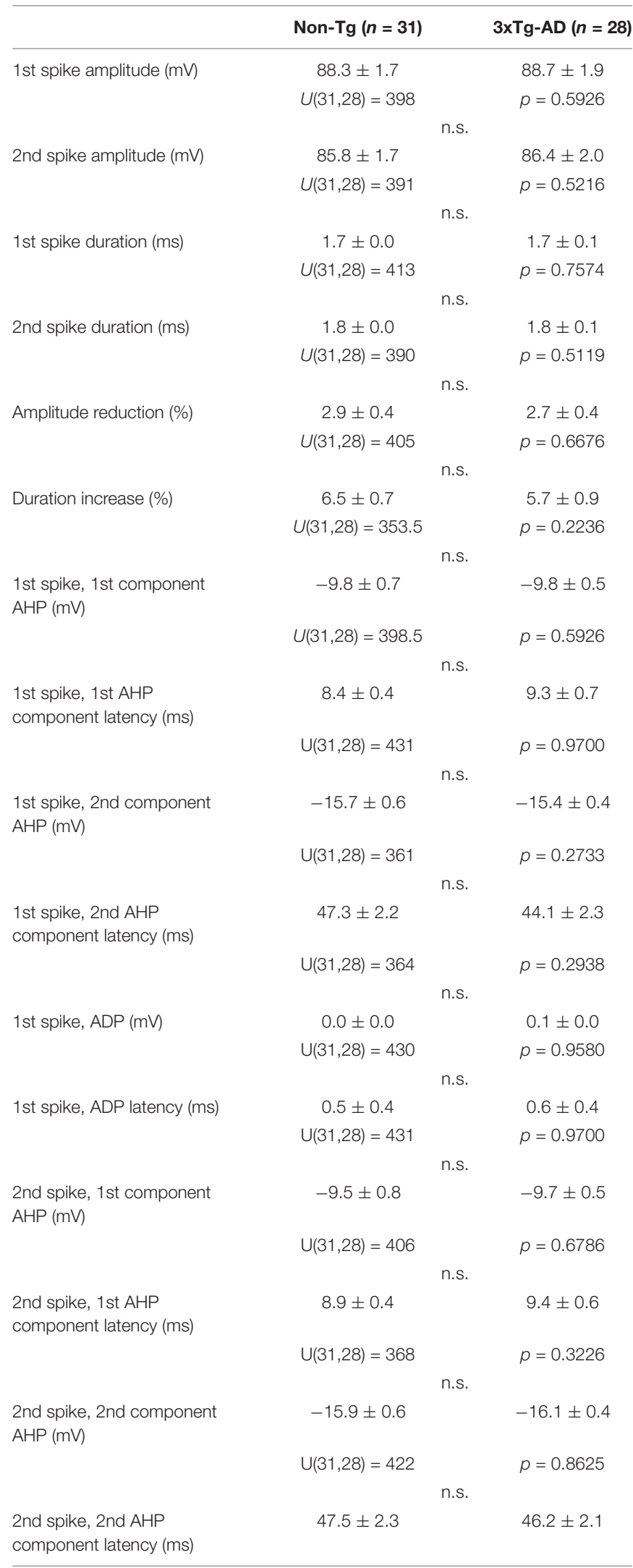

(Continued)
TABLE 5 | Continued

\begin{tabular}{|c|c|c|}
\hline & Non-Tg $(n=31)$ & $3 \times T g-A D(n=28)$ \\
\hline & $U(31,28)=400$ & $p=0.6136$ \\
\hline & \multicolumn{2}{|c|}{ n.s. } \\
\hline \multirow[t]{3}{*}{ 2nd spike, ADP (mV) } & $0.0 \pm 0.0$ & $0.3 \pm 0.3$ \\
\hline & $U(31,28)=418.5$ & $p=0.8154$ \\
\hline & \multicolumn{2}{|c|}{ n.s. } \\
\hline \multirow{2}{*}{$\begin{array}{l}\text { 2nd spike, ADP latency } \\
\text { (ms) }\end{array}$} & $0.0 \pm 0.0$ & $2.9 \pm 0.4$ \\
\hline & $U(31,28)=418.5$ & $p=0.8154$ \\
\hline
\end{tabular}

n, number of cells; n.s., not statistically significant.

Mann-Whitney $U$ tests and corresponding exact $p$-values.

similar proportions in non-Tg $(29 \%, n=9$ out of 31$)$ and $3 x \mathrm{Tg}-\mathrm{AD}$ pyramidal cells $(29 \%, n=8$ out of $28, p=1.000$, Figures 6B,C).

\section{DISCUSSION}

Here we studied glucose metabolism of juvenile supragranular pyramidal cells and its early alteration in a mouse model of AD. Using intracellular glucose imaging and scRT-mPCR, we found that glucose uptake was effective in juvenile pyramidal cells and was not altered in 3xTg-AD mice. We also observed that both glycolysis and pentose phosphate pathway were active under resting condition. Interestingly, in $3 x \mathrm{Tg}-\mathrm{AD}$ neurons the pentose phosphate pathway was reduced in favor of glycolysis (Figure 7). IAA application also disclosed that another glucose metabolic pathway might be active in $3 \mathrm{xTg}$-AD neurons. The scRT-mPCR analysis allowed to establish the three expression profile of glucose metabolism key genes in pyramidal neurons, which appeared qualitatively unaltered in $3 \times \mathrm{Tg}-\mathrm{AD}$ mice. This indicates that the metabolic alterations observed in 3x-Tg-AD pyramidal neurons are possibly due to post-transcriptional modifications.

\section{Intracellular Glucose Imaging in Pyramidal Cells}

We visualized the dynamics of intracellular glucose level using a genetically encoded biosensor exhibiting changes in FRET upon glucose binding but insensitive to phosphorylated glucose or glycolytic intermediates (Fehr et al., 2003; Deuschle et al., 2005; John et al., 2008; Takanaga et al., 2008; Bittner et al., 2011; Hou et al., 2011; Barros et al., 2013). The glucose sensor FLII12Pglu-700 $\mu \delta 6$ was transduced using a Sindbis vector which exhibits a strong tropism toward pyramidal cells (Chen et al., 2000; Lendvai et al., 2000; Furuta et al., 2001; Drobac et al., 2010). Consistently, a large majority of transduced cells were immunopositive for Satb2 (Figure 1), a transcription factor of pyramidal cells (Britanova et al., 2008; Tasic et al., 2016). Given that not all upper-layer pyramidal cells express Satb2 (Britanova et al., 2008; Tasic et al., 2016), the proportion of excitatory neurons expressing the glucose sensor is likely to be higher. Thus, our glucose imaging experiments performed in layer II and III 

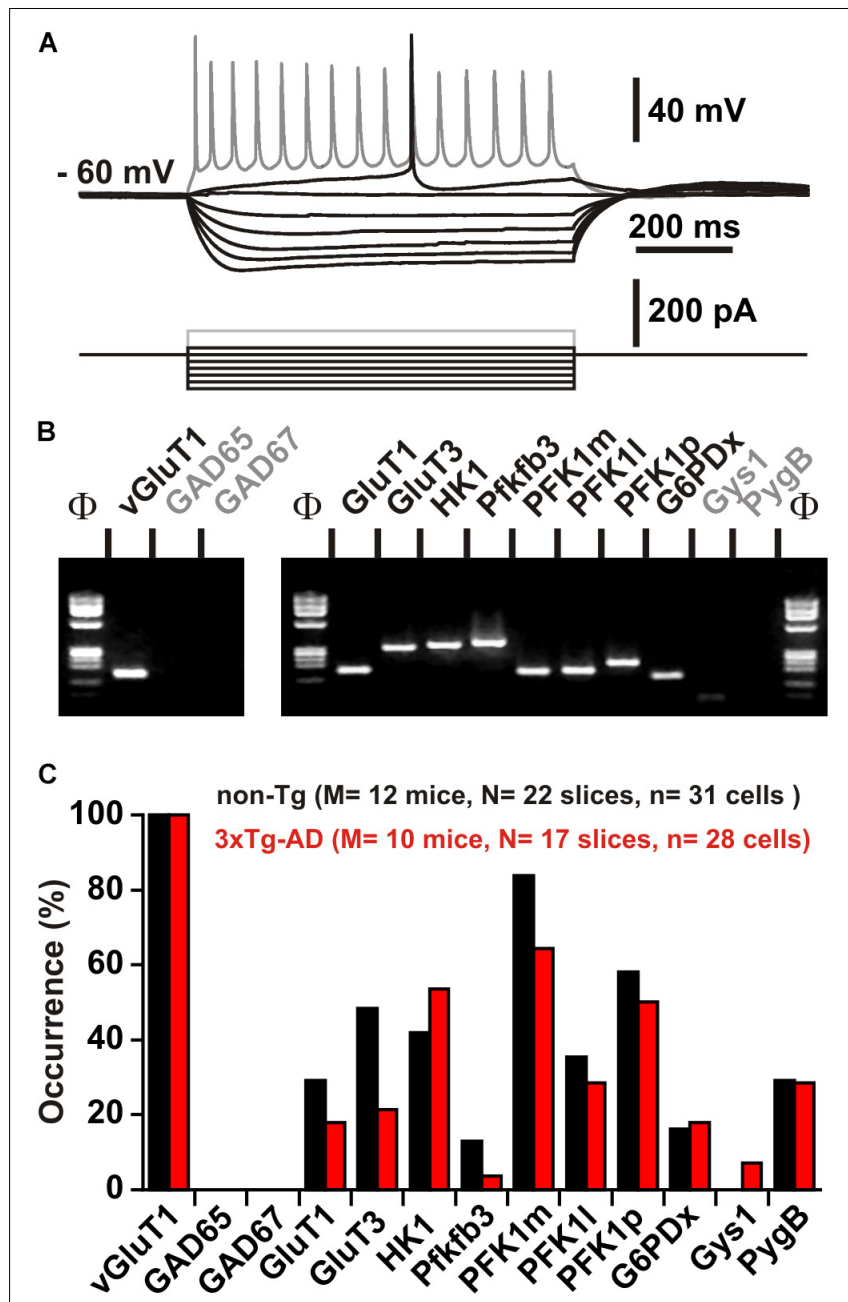

FIGURE 6 | Characterization of key molecular elements of glucose metabolism in layer II and III pyramidal cells. (A) Voltage responses (upper traces) induced by injection of current pulses (bottom traces) in a non-Tg layer II and III pyramidal cell. In response to just-above-threshold current pulse, this neuron fired an action potential with a long lasting biphasic AHP (middle trace). Near saturation it showed the typical firing of a regular spiking neuron with marked frequency adaptation and spike amplitude accommodation (shaded trace). (B) The pyramidal cell shown in (A) expressed vGluT1, GluT1, GluT3, HK1, pfkfb3, PFK1m, PFK1I, PFK1p, and G6PDx. (C) Histograms showing the expression profiles of key molecular elements of glucose metabolism in layer II and III pyramidal cells of non-Tg (black) and 3xTg-AD mice $(r e d)$. No statistically significant difference in the occurrence of genes was observed. Note the very low occurrence of pfkfb3 and Gys1 (glycogen synthase) in pyramidal neurons.

largely reflects the metabolic activity of upper layer pyramidal cells.

\section{Glucose Uptake}

In addition to GluT3, a well established neuronal glucose transporter (Nagamatsu et al., 1992; McCall et al., 1994; Fields et al., 1999), we also detected GluT1 in a minority of pyramidal cells. Although, GluT1 is more classically described in glial and endothelial cells (Kacem et al., 1998; McEwen and Reagan, 2004;
Simpson et al., 2007; Winkler et al., 2015), recent transcriptomic studies have revealed GluT1 expression in neurons (Cahoy et al., 2008), including layer II and III cortical pyramidal cells (Tasic et al., 2016). These observations indicate that juvenile supragranular pyramidal cells express GluT3 and/or GluT1 transcripts.

Intracellular glucose imaging revealed that juvenile pyramidal cells have the capacity to take up glucose (Figure 2). This is consistent with the relatively low rate of glucose uptake reported in resting cortical neurons (Chuquet et al., 2010; Diaz-Garcia et al., 2017). Furthermore, we observed a low occurrence of GluT1 and GluT3 mRNAs (Figure 6), in agreement with the low expression level of these transporters in rodents during the first postnatal weeks (Khan et al., 1999; Vannucci and Simpson, 2003). Since scRT-mPCR sensitivity is limited by the abundance of transcripts and by the amount of cytoplasm collected (Cauli and Lambolez, 2010; Devienne et al., 2018), this technique barely detects transcripts expressed at a very low single cell level. This could explain the relatively low level of GluT1 and GluT3 detection in pyramidal cells despite a glucose uptake capacity that we observed in virtually all analyzed neurons. In addition, since the proportion of neurons expressing at least one GluT is higher than that of those expressing a given GluT, a lack of GluT1 expression is likely to be functionally compensated by expression of GluT3 and vice versa. Along this line, functional compensation of glucose transport could be also achieved by other glucose transporters such as GluT6 whose transcripts have been consistently reported in cortical neurons (Cahoy et al., 2008; Tasic et al., 2016). Altogether, our observations indicate that at this juvenile stage, when energy metabolism is still heavily dependent on ketone bodies (Nehlig, 1999), pyramidal cells can already use glucose.

Neither GluT1 and 3 expression nor glucose uptake capacity was altered in juvenile $3 x \mathrm{Tg}-\mathrm{AD}$ pyramidal cells. Indeed, quantitative impairments in GluTs expression and glucose utilization have only been reported after 6 months of age in 3xTgAD mice (Nicholson et al., 2010; Chen et al., 2012; Ding et al., 2013).

\section{Glucose Fate in Juvenile Pyramidal Cells}

HK1, the predominant brain hexokinase isoform (Wilkin and Wilson, 1977; Fields et al., 1999; Khan et al., 1999) was detected in a substantial proportion of pyramidal neurons confirming its expression at a relatively low level in this cell type (Tasic et al., 2016). This suggests that juvenile pyramidal cells have already the ability to metabolize glucose into glucose- 6 phosphate as indicated by our glucose imaging observations (Figures 3, 7).

As previously observed (Zeitschel et al., 1996; Bigl et al., 2003; Cahoy et al., 2008; Tasic et al., 2016), the key enzymes of glycolysis PFK1m and PFK1p, but also FPK1l to a lesser extent, were frequently detected in juvenile pyramidal cells. In contrast, pfkfb3 was rarely detected (Tasic et al., 2016). These molecular data indicate that pyramidal cells are well equipped for glycolysis. To evaluate functionally glycolysis fluxes in slices, we applied $200 \mu \mathrm{M}$ IAA for $30 \mathrm{~min}$. Such a treatment achieves an efficient glycolysis inhibition reducing NADH level within 5 min (Gordon et al., 2008) in agreement with IAA-induced G3PDH 

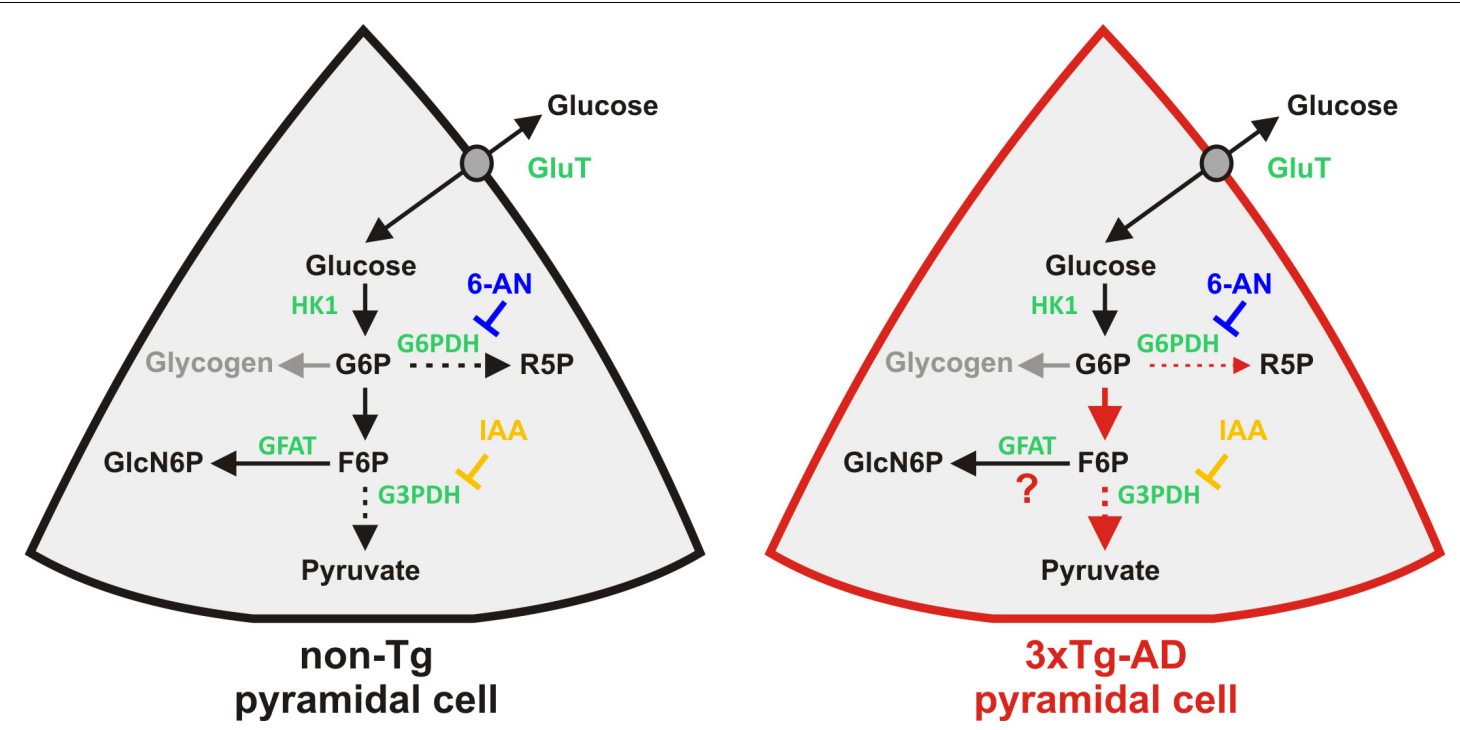

FIGURE 7 | Resting glucose metabolism of juvenile pyramidal cells and its alterations in 3xTg-AD mice. Glucose uptake is facilitated via glucose transporters (GluT). Once in the cytoplasm glucose phosphorylation by Hexokinase1 (HK1) yields to glucose 6-phosphate (G6P), the common substrate of different metabolic pathways Glucose-6-phosphate dehydrogenase (G6PDH) is the rate limiting enzyme of the pentose phosphate pathway leading to ribose-5-phosphate (R5P). Pentose phosphate pathway is blocked by the G6PDH inhibitor, 6-aminonicotinamide (6-AN). G6P can also be isomerized into fructose-6-phosphate (F6P), a common intermediate of the glycolysis and the hexosamine biosynthetic pathway. Glycolysis is blocked by lodoacetic acid (IAA) inhibiting glyceraldehyde-3-phosphate dehydrogenase (G3PDH). Glutamine:fructose-6-phosphate amidotransferase (GFAT), the rate limiting enzyme of the hexosamine biosynthetic pathway, converts fructose-6-phosphate and glutamine into glucosamine-6-phosphate (GlcN6P) and glutamate (glutamine and glutamate are omitted for the sake of simplicity). G6P is also the precursor of glycogen whose synthesis is normally absent in neurons (gray arrow). Dashed arrows indicate multisteps reactions. Functional changes in 3xTg-AD neurons are depicted by red arrows. Thicker and thinner arrows denote increased and decreased pathways, respectively.

inhibition, all the while minimizing unspecific effects (Dringen et al., 1993). Blockade of the glycolytic flux generates a progressive accumulation of glucose-6-phosphate (Bittner C.X. et al., 2010) which in turn strongly inhibits HK1 (Liu et al., 1999), leading to an intracellular glucose increase (John et al., 2008). During IAA exposure, we consistently observed a delayed accumulation of intracellular glucose. Confirming a recent report (Diaz-Garcia et al., 2017), our results collectively reveal an active glycolysis in juvenile pyramidal cells (Figures 4A, 7).

G6PDx is a major rate limiting enzyme of the pentose phosphate pathway. In agreement with previous observations (Ninfali et al., 1998; Cahoy et al., 2008; Tasic et al., 2016), we detected its transcripts suggesting that juvenile pyramidal cells can also use glucose for the pentose phosphate pathway. To determine functionally the activity of this metabolic pathway we used 6-AN, an inhibitor of two key enzymes, G6PDH and 6phosphogluconate dehydrogenase (Lange and Proft, 1970; Kohler et al., 1970) which has a mild impact on glycolysis in the short term (Hothersall et al., 1981; Haghighat and McCandless, 1997). Blockade of the pentose phosphate pathway with 6-AN induced an increase of intracellular glucose in non-Tg juvenile pyramidal cells (Figures 4B, 7). Taken together, our data indicate that pentose phosphate pathway is active in these neurons.

Under physiological conditions, glycogen is absent from neurons (Vilchez et al., 2007). Consistent with previous reports (Zeisel et al., 2015; Tasic et al., 2016), the glycogen synthase (Gys1), and the glycogen phosphylase (PygB), were rarely detected in non-Tg pyramidal cells.
Overall our molecular and imaging data indicate that the glycolysis and the pentose phosphate pathway are the two main active glucose pathways in juvenile pyramidal cells (Figure 7).

\section{Alteration of Glucose Metabolic Pathways in 3xTg-AD Pyramidal Cells}

We observed a higher glycolytic activity and a less active pentose phosphate pathway in 3xTg-AD juvenile pyramidal neurons (Figure 7). Interestingly a NMR study has reported an increased neuronal glycolysis in 7-months old 3xTg-AD mice (Sancheti et al., 2014b) indicating that the higher glycolytic activity develops early and persists before aging (Sancheti et al., 2014a). Consistently, a recent metabolomic study revealed a higher lactate plasma level in 8-months old 3xTg-AD mice (Sanguinetti et al., 2018) that could result from a higher neuronal glycolytic flux (Diaz-Garcia et al., 2017).

Our molecular observations did not reveal any significant change in the expression profile of key molecular elements of glucose metabolism in 3xTg-AD juvenile pyramidal cells. However given the detection limits of the scRT-mPCR discussed above and the relatively low occurrence G6PDx transcripts, it is possible that the lower pentose phosphate pathway observed in $3 x \mathrm{Tg}-\mathrm{AD}$ mice derives from a reduction of G6PDx expression. To our knowledge, changes in the expression profile of key molecular elements of glucose metabolism in 3xTg-AD mice have only been reported after 6 months of age (Chen et al., 2012; Ding et al., 2013). This suggests that the early alterations of metabolic activity are likely mediated by post-transcriptional and/or 
post-translational modifications. Interestingly, microRNA-34a overexpression reduces G6PDH protein level and was found to be increased in the temporal cortex of both $3 x \mathrm{Tg}-\mathrm{AD}$ mice and $\mathrm{AD}$ patients (Sarkar et al., 2016). Similarly, the activity of several key elements controlling glucose pathways are regulated at the posttranslational level (Khan et al., 1999; Almeida et al., 2004; Vilchez et al., 2007; Bolanos et al., 2008; Herrero-Mendez et al., 2009).

Given the low level of detection of pfkfb3 (Figure 6; Tasic et al., 2016), it is unlikely that $3 \times \mathrm{Tg}-\mathrm{AD}$ pyramidal cells upregulate glycolysis via fructose 2,6-bisphosphate production (Almeida et al., 2004; Herrero-Mendez et al., 2009). Exposure to A $\beta$ peptides has been shown to increase the glycolytic activity of astrocytes (Allaman et al., 2010). It would be interesting to determine whether $A \beta$ peptides, even at very low level, could be responsible for the early alterations we observed in 3xTg-AD pyramidal cells. Further investigations will be needed to elucidate the underlying mechanisms.

Upon IAA application, we observed a transient increase in glucose utilization in $3 x T g-A D$ pyramidal cells. A rerouting of glucose utilization toward the pentose phosphate pathway and/or glycogenesis is unlikely given that the increased glucose consumption induced by IAA persisted in presence of 6-AN (Figure 4C) and that pyramidal neurons rarely express glycogen synthase (Figure 6; Zeisel et al., 2015; Tasic et al., 2016). An alternative possibility would be an increased glucose utilization via the hexosamine biosynthetic pathway which competes with glycolysis for fructose-6-phosphate (Figure 7). The entry in this metabolic pathway is controlled by the rate limiting enzyme glutamine:fructose-6-phosphate amidotransferase (GFAT), which converts fructose-6-phosphate and glutamine to glucosamine-6-phosphate and glutamate (Buse, 2006). Interestingly, 3xTg-AD mice exhibit a temporary increased brain level of glutamine (Sancheti et al., 2014a,b) that could account for its higher plasma level (Sanguinetti et al., 2018). Thus, upon glycolysis inhibition, the hexosamine biosynthetic pathway could be favored by an enhanced availability of the two GFAT substrates in these mice. Indeed, IAA will induce a retrograde increase of the glycolysis intermediaries before HK inhibition by glucose-6-phosphate (Liu et al., 1999) and subsequent glucose accumulation (John et al., 2008). Thus fructose-6-phosphate would be then transiently available to feed the hexosamine biosynthetic pathway. Glutamine synthesis largely relies on astrocytes metabolism. In slices, IAA application would also affect astrocytes glycolysis and would lead to a shortage in glutamine production. Therefore, an enhanced flux of the hexosamine biosynthetic pathway in $3 x$ Tg-AD pyramidal cells is expected to be transient. This hypothesis is compatible with the fast inhibition of G3PDH by IAA in astrocytes (Gordon et al., 2008) and the kinetics of the transient decrease in intracellular glucose observed (Figure 4).

Interestingly, the hexosamine biosynthetic pathway is essential for $\mathrm{O}-\mathrm{N}$-acetylglucosamine glycosylation, a process that protects tau protein against hyperphosphorylation (Liu et al., 2009; Gatta et al., 2016). An increased activity of this pathway might represent an early adaptive mechanism to prevent and/or delay neurofibrillary tangles formation in pyramidal cells. The later impairment of glucose uptake (Nicholson et al., 2010; Ding et al., 2013) and decreased levels of glutamine (Sancheti et al., 2014a) observed in $3 \mathrm{xTg}$-AD mice is likely to reduce the activity of the hexosamine pathway leading to tau hyperphosphorylation and tangles formation (Oddo et al., 2003; Carroll et al., 2010; Gatta et al., 2016).

\section{CONCLUSION}

Despite a low cerebral glucose metabolism in suckling rodents (Nehlig, 1999), its qualitative alterations in 3xTg-AD pyramidal cells at a very early stage may have deleterious consequences for their activity and survival in the long-term. Indeed, neurons are poorly equipped to detoxify methylglyoxal, a harmful glycolysis byproduct (Belanger et al., 2011). An increased glycolytic activity is therefore expected to alter pyramidal cells survival (HerreroMendez et al., 2009). Similarly, a decreased pentose phosphate pathway would reduce the capacity of neurons to produce glutathione, impairing their ability to detoxify reactive oxygen species (Vaughn and Deshmukh, 2008). A higher glycolysis activity combined with a reduced pentose phosphate pathway would dramatically increase pyramidal cell vulnerability. This could contribute to their degeneration which occurs before amyloid deposition (Bittner T. et al., 2010). Further investigations will be required to determine how these metabolic alterations evolve during maturation and to identify their underlying mechanisms, which could provide potential targets for drugmodifying therapies.

\section{AUTHOR CONTRIBUTIONS}

BC, JP, and GB conceived and designed the experiments. JP, XT, JLD, ÉF, and BC performed the experiments. JP and BC analyzed the data. JP, BC, and GB interpreted the results. $\mathrm{RH}, \mathrm{RL}$, and EG contributed reagents and materials. JP, BC, and GB wrote the manuscript.

\section{FUNDING}

This work was supported by the Agence Nationale pour la Recherche (ANR 2011 MALZ 003 01: BC and GB and ANR-17-CE37-0010-03: BC), "IHU Institut de Neurosciences Translationelles de Paris," (ANR-10-IAIHU-06: BC), the Fondation pour la Recherche sur le Cerveau/Rotary Club de France (AOE-7 "Espoir en tête 2014": BC) and by the association France Alzheimer and Fondation de France (ASTROinAD: BC and GB).

\section{ACKNOWLEDGMENTS}

We thank the animal and imaging facilities of the IBPS (Paris, France) and Drs Alexandre Mourot and Felipe Barros for their comments on the manuscript. 


\section{REFERENCES}

Allaman, I., Belanger, M., and Magistretti, P. J. (2011). Astrocyte-neuron metabolic relationships: for better and for worse. Trends Neurosci. 34, 76-87. doi: 10.1016/ j.tins.2010.12.001

Allaman, I., Gavillet, M., Belanger, M., Laroche, T., Viertl, D., Lashuel, H. A., et al. (2010). Amyloid-beta aggregates cause alterations of astrocytic metabolic phenotype: impact on neuronal viability. J. Neurosci. 30, 3326-3338. doi: 10.1523/JNEUROSCI.5098-09.2010

Almeida, A., Moncada, S., and Bolanos, J. P. (2004). Nitric oxide switches on glycolysis through the AMP protein kinase and 6-phosphofructo-2-kinase pathway. Nat. Cell Biol. 6, 45-51. doi: 10.1038/ncb1080

Ascoli, G. A., Alonso-Nanclares, L., Anderson, S. A., Barrionuevo, G., AvidesPiccione, R., Burkhalter, A., et al. (2008). Petilla terminology: nomenclature of features of GABAergic interneurons of the cerebral cortex. Nat. Rev. Neurosci. 9, 557-568. doi: 10.1038/nrn2402

Barros, L. F., San, M. A., Sotelo-Hitschfeld, T., Lerchundi, R., FernandezMoncada, I., Ruminot, I., et al. (2013). Small is fast: astrocytic glucose and lactate metabolism at cellular resolution. Front. Cell. Neurosci. 7:27. doi: 10.3389/fncel.2013.00027

Belanger, M., Yang, J., Petit, J. M., Laroche, T., Magistretti, P. J., and Allaman, I. (2011). Role of the glyoxalase system in astrocyte-mediated neuroprotection. J. Neurosci. 31, 18338-18352. doi: 10.1523/JNEUROSCI.1249-11.2011

Bigl, M., Apelt, J., Eschrich, K., and Schliebs, R. (2003). Cortical glucose metabolism is altered in aged transgenic Tg2576 mice that demonstrate Alzheimer plaque pathology. J. Neural Transm. 110, 77-94.

Bilger, A., and Nehlig, A. (1992). Quantitative histochemical changes in enzymes involved in energy metabolism in the rat brain during postnatal development. II. Glucose-6-phosphate dehydrogenase and beta-hydroxybutyrate dehydrogenase. Int. J. Dev. Neurosci. 10, 143-152. doi: 10.1016/0736-5748(92)90042-X

Bittner, C. X., Loaiza, A., Ruminot, I., Larenas, V., Sotelo-Hitschfeld, T., Gutierrez, R., et al. (2010). High resolution measurement of the glycolytic rate. Front. Neuroenergetics 2:26. doi: 10.3389/fnene.2010.00026

Bittner, T., Fuhrmann, M., Burgold, S., Ochs, S. M., Hoffmann, N., Mitteregger, G., et al. (2010). Multiple events lead to dendritic spine loss in triple transgenic Alzheimer's disease mice. PLoS One 5:e15477. doi: 10.1371/journal.pone. 0015477

Bittner, C. X., Valdebenito, R., Ruminot, I., Loaiza, A., Larenas, V., SoteloHitschfeld, T., et al. (2011). Fast and reversible stimulation of astrocytic glycolysis by $\mathrm{k}+$ and a delayed and persistent effect of glutamate. J. Neurosci. 31, 4709-4713. doi: 10.1523/JNEUROSCI.5311-10.2011

Bolanos, J. P., Gado-Esteban, M., Herrero-Mendez, A., Fernandez-Fernandez, S., and Almeida, A. (2008). Regulation of glycolysis and pentose-phosphate pathway by nitric oxide: impact on neuronal survival. Biochim. Biophys. Acta 1777, 789-793. doi: 10.1016/j.bbabio.2008.04.011

Braak, H., and Braak, E. (1991). Neuropathological stageing of Alzheimer-related changes. Acta Neuropathol. 82, 239-259. doi: 10.1007/BF00308809

Britanova, O., de Juan, R. C., Cheung, A., Kwan, K. Y., Schwark, M., Gyorgy, A., et al. (2008). Satb2 is a postmitotic determinant for upper-layer neuron specification in the neocortex. Neuron 57, 378-392. doi: 10.1016/j.neuron.2007. 12.028

Buse, M. G. (2006). Hexosamines, insulin resistance, and the complications of diabetes: current status. Am. J. Physiol. Endocrinol. Metab. 290, E1-E8. doi: 10.1152/ajpendo.00329.2005

Cahoy, J. D., Emery, B., Kaushal, A., Foo, L. C., Zamanian, J. L., Christopherson, K. S., et al. (2008). A transcriptome database for astrocytes, neurons, and oligodendrocytes: a new resource for understanding brain development and function. J. Neurosci. 28, 264-278. doi: 10.1523/JNEUROSCI.4178-07.2008

Carroll, J. C., Rosario, E. R., Kreimer, S., Villamagna, A., Gentzschein, E., Stanczyk, F. Z., et al. (2010). Sex differences in beta-amyloid accumulation in 3xTg-AD mice: role of neonatal sex steroid hormone exposure. Brain Res. 1366, 233-245. doi: 10.1016/j.brainres.2010.10.009

Cauli, B., Audinat, E., Lambolez, B., Angulo, M. C., Ropert, N., Tsuzuki, K., et al. (1997). Molecular and physiological diversity of cortical nonpyramidal cells. J. Neurosci. 17, 3894-3906. doi: 10.1523/JNEUROSCI.17-10-03894.1997

Cauli, B., and Hamel, E. (2010). Revisiting the role of neurons in neurovascular coupling. Front. Neuroenergetics 2:9. doi: 10.3389/fnene.2010.00009
Cauli, B., and Lambolez, B. (2010). "Gene analysis of single cells," in Unravelling Single Cell Genomics: Micro and Nanotools, eds N. Bontoux and M. C. Potier (Cambridge: RSC publishing), 81-92. doi: 10.1039/9781849732284-00081

Chen, B. E., Lendvai, B., Nimchinsky, E. A., Burbach, B., Fox, K., and Svoboda, K. (2000). Imaging high-resolution structure of GFP-expressing neurons in neocortex in vivo. Learn. Mem. 7, 433-441. doi: 10.1101/lm.32700

Chen, Y., Tian, Z., Liang, Z., Sun, S., Dai, C. L., Lee, M. H., et al. (2012). Brain gene expression of a sporadic (icv-STZ Mouse) and a familial mouse model (3xTgAD Mouse) of Alzheimer's disease. PLoS One 7:e51432. doi: 10.1371/journal. pone.0051432

Choi, H. B., Gordon, G. R., Zhou, N., Tai, C., Rungta, R. L., Martinez, J., et al. (2012). Metabolic communication between astrocytes and neurons via bicarbonate-responsive soluble adenylyl cyclase. Neuron 75, 1094-1104. doi: 10.1016/j.neuron.2012.08.032

Chuquet, J., Quilichini, P., Nimchinsky, E. A., and Buzsaki, G. (2010). Predominant enhancement of glucose uptake in astrocytes versus neurons during activation of the somatosensory cortex. J. Neurosci. 30, 15298-15303. doi: 10.1523/ JNEUROSCI.0762-10.2010

Deuschle, K., Okumoto, S., Fehr, M., Looger, L. L., Kozhukh, L., and Frommer, W. B. (2005). Construction and optimization of a family of genetically encoded metabolite sensors by semirational protein engineering. Protein Sci. 14, 2304-2314. doi: 10.1110/ps.051508105

Devienne, G., Le Gac, B., Piquet, J., and Cauli, B. (2018). Single cell multiplex reverse transcription polymerase chain reaction after patch-clamp. J. Vis. Exp. 136:e57627. doi: 10.3791/57627

Diaz-Garcia, C. M., Mongeon, R., Lahmann, C., Koveal, D., Zucker, H., and Yellen, G. (2017). Neuronal stimulation triggers neuronal glycolysis and not lactate uptake. Cell Metab. 26, 361-374. doi: 10.1016/j.cmet.2017.06.021

Ding, F., Yao, J., Rettberg, J. R., Chen, S., and Brinton, R. D. (2013). Early decline in glucose transport and metabolism precedes shift to ketogenic system in female aging and Alzheimer's mouse brain: implication for bioenergetic intervention. PLoS One 8:e79977. doi: 10.1371/journal.pone.0079977

Dodt, H. U., and Zieglgansberger, W. (1998). Visualization of neuronal form and function in brain slices by infrared videomicroscopy. Histochem. J. 30, 141-152. doi: 10.1023/A:1003291218707

Dringen, R., Wiesinger, H., and Hamprecht, B. (1993). Uptake of L-lactate by cultured rat brain neurons. Neurosci. Lett. 163, 5-7. doi: 10.1016/0304-3940(93) 90215-7

Drobac, E., Tricoire, L., Chaffotte, A. F., Guiot, E., and Lambolez, B. (2010). Calcium imaging in single neurons from brain slices using bioluminescent reporters. J. Neurosci. Res. 88, 695-711. doi: 10.1002/jnr. 22249

Dubois, B., Hampel, H., Feldman, H. H., Scheltens, P., Aisen, P., Andrieu, S., et al. (2016). Preclinical Alzheimer's disease: definition, natural history, and diagnostic criteria. Alzheimers Dement. 12, 292-323. doi: 10.1016/j.jalz.2016. 02.002

Fehr, M., Lalonde, S., Lager, I., Wolff, M. W., and Frommer, W. B. (2003). In vivo imaging of the dynamics of glucose uptake in the cytosol of COS-7 cells by fluorescent nanosensors. J. Biol. Chem. 278, 19127-19133. doi: 10.1074/jbc. M301333200

Fernandez-Fernandez, S., Almeida, A., and Bolanos, J. P. (2012). Antioxidant and bioenergetic coupling between neurons and astrocytes. Biochem. J. 443, 3-11. doi: 10.1042/BJ20111943

Fields, H. M., Rinaman, L., and Devaskar, S. U. (1999). Distribution of glucose transporter isoform-3 and hexokinase I in the postnatal murine brain. Brain Res. 846, 260-264. doi: 10.1016/S0006-8993(99)01979-4

Fox, P. T., and Raichle, M. E. (1986). Focal physiological uncoupling of cerebral blood flow and oxidative metabolism during somatosensory stimulation in human subjects. Proc. Natl. Acad. Sci. U.S.A. 83, 1140-1144. doi: 10.1073/pnas. 83.4.1140

Fox, P. T., Raichle, M. E., Mintun, M. A., and Dence, C. (1988). Nonoxidative glucose consumption during focal physiologic neural activity. Science 241, 462-464. doi: 10.1126/science.3260686

Furuta, T., Tomioka, R., Taki, K., Nakamura, K., Tamamaki, N., and Kaneko, T. (2001). In vivo transduction of central neurons using recombinant Sindbis virus: golgi-like labeling of dendrites and axons with membrane-targeted fluorescent proteins. J. Histochem. Cytochem. 49, 1497-1508. doi: 10.1177/ 002215540104901203 
Gatta, E., Lefebvre, T., Gaetani, S., dos, S. M., Marrocco, J., Mir, A. M., et al. (2016). Evidence for an imbalance between Tau O-GlcNAcylation and phosphorylation in the hippocampus of a mouse model of Alzheimer's disease. Pharmacol. Res. 105, 186-197. doi: 10.1016/j.phrs.2016.01.006

Gordon, G. R., Choi, H. B., Rungta, R. L., Ellis-Davies, G. C., and MacVicar, B. A. (2008). Brain metabolism dictates the polarity of astrocyte control over arterioles. Nature 456, 745-749. doi: 10.1038/nature07525

Haghighat, N., and McCandless, D. W. (1997). Effect of 6-aminonicotinamide on metabolism of astrocytes and C6-glioma cells. Metab. Brain Dis. 12, 29-45. doi: 10.1007/BF02676352

Hardy, J., and Selkoe, D. J. (2002). The amyloid hypothesis of Alzheimer's disease: progress and problems on the road to therapeutics. Science 297, 353-356. doi: 10.1126/science.1072994

Hepp, R., Tricoire, L., Hu, E., Gervasi, N., Paupardin-Tritsch, D., Lambolez, B., et al. (2007). Phosphodiesterase type 2 and the homeostasis of cyclic GMP in living thalamic neurons. J. Neurochem. 102, 1875-1886. doi: 10.1111/j.14714159.2007.04657.x

Herrero-Mendez, A., Almeida, A., Fernandez, E., Maestre, C., Moncada, S., and Bolanos, J. P. (2009). The bioenergetic and antioxidant status of neurons is controlled by continuous degradation of a key glycolytic enzyme by APC/CCdh1. Nat. Cell Biol. 11, 747-752. doi: 10.1038/ncb1881

Hothersall, J. S., Zubairu, S., McLean, P., and Greenbaum, A. L. (1981). Alternative pathways of glucose utilization in brain; changes in the pattern of glucose utilization in brain resulting from treatment of rats with 6-aminonicotinamide. J. Neurochem. 37, 1484-1496. doi: 10.1111/j.1471-4159.1981.tb06318.x

Hou, B. H., Takanaga, H., Grossmann, G., Chen, L. Q., Qu, X. Q., Jones, A. M., et al. (2011). Optical sensors for monitoring dynamic changes of intracellular metabolite levels in mammalian cells. Nat. Protoc. 6, 1818-1833. doi: 10.1038/ nprot.2011.392

Hu, E., Demmou, L., Cauli, B., Gallopin, T., Geoffroy, H., Harris-Warrick, R. M., et al. (2011). VIP, CRF, and PACAP act at distinct receptors to elicit different cAMP/PKA dynamics in the neocortex. Cereb. Cortex 21, 708-718. doi: 10.1093/cercor/bhq143

Iadecola, C., and Nedergaard, M. (2007). Glial regulation of the cerebral microvasculature. Nat. Neurosci. 10, 1369-1376. doi: 10.1038/nn2003

John, S. A., Ottolia, M., Weiss, J. N., and Ribalet, B. (2008). Dynamic modulation of intracellular glucose imaged in single cells using a FRET-based glucose nanosensor. Pflugers Arch. 456, 307-322. doi: 10.1007/s00424-007-0395-Z

Kacem, K., Lacombe, P., Seylaz, J., and Bonvento, G. (1998). Structural organization of the perivascular astrocyte endfeet and their relationship with the endothelial glucose transporter: a confocal microscopy study. Glia 23, 1-10. doi: 10.1002/ (SICI) 1098-1136(199805)23:1<1::AID-GLIA1>3.0.CO;2-B

Karagiannis, A., Gallopin, T., David, C., Battaglia, D., Geoffroy, H., Rossier, J., et al. (2009). Classification of NPY-expressing neocortical interneurons. J. Neurosci. 29, 3642-3659. doi: 10.1523/JNEUROSCI.0058-09.2009

Kasischke, K. A., Vishwasrao, H. D., Fisher, P. J., Zipfel, W. R., and Webb, W. W. (2004). Neural activity triggers neuronal oxidative metabolism followed by astrocytic glycolysis. Science 305, 99-103. doi: 10.1126/science.1096485

Khan, J. Y., Rajakumar, R. A., McKnight, R. A., Devaskar, U. P., and Devaskar, S. U. (1999). Developmental regulation of genes mediating murine brain glucose uptake. Am. J. Physiol. 276, R892-R900.

Kohler, E., Barrach, H., and Neubert, D. (1970). Inhibition of NADP dependent oxidoreductases by the 6-aminonicotinamide analogue of NADP. FEBS Lett. 6, 225-228. doi: 10.1016/0014-5793(70)80063-1

Lacroix, A., Toussay, X., Anenberg, E., Lecrux, C., Ferreiros, N., Karagiannis, A., et al. (2015). COX-2-derived prostaglandin E2 produced by pyramidal neurons contributes to neurovascular coupling in the rodent cerebral cortex. J. Neurosci. 35, 11791-11810. doi: 10.1523/JNEUROSCI.0651-15.2015

Lambolez, B., Audinat, E., Bochet, P., Crepel, F., and Rossier, J. (1992). AMPA receptor subunits expressed by single Purkinje cells. Neuron 9, 247-258. doi: 10.1016/0896-6273(92)90164-9

Lange, K., and Proft, E. R. (1970). Inhibition of the 6-phosphogluconate dehydrogenase in the rat kidney by 6-aminonicotinamide. Naunyn Schmiedebergs Arch. Pharmakol. 267, 177-180. doi: 10.1007/BF00999399

Lecrux, C., Toussay, X., Kocharyan, A., Fernandes, P., Neupane, S., Levesque, M., et al. (2011). Pyramidal neurons are "neurogenic hubs" in the neurovascular coupling response to whisker stimulation. J. Neurosci. 31, 9836-9847. doi: 10.1523/JNEUROSCI.4943-10.2011
Lee, S., Hjerling-Leffler, J., Zagha, E., Fishell, G., and Rudy, B. (2010). The largest group of superficial neocortical GABAergic interneurons expresses ionotropic serotonin receptors. J. Neurosci. 30, 16796-16808. doi: 10.1523/JNEUROSCI. 1869- 10.2010

Lendvai, B., Stern, E. A., Chen, B., and Svoboda, K. (2000). Experience-dependent plasticity of dendritic spines in the developing rat barrel cortex in vivo. Nature 404, 876-881. doi: 10.1038/35009107

Lerchundi, R., Fernandez-Moncada, I., Contreras-Baeza, Y., Sotelo-Hitschfeld, T., Machler, P., Wyss, M. T., et al. (2015). NH4+ triggers the release of astrocytic lactate via mitochondrial pyruvate shunting. Proc. Natl. Acad. Sci. U.S.A. 112, 11090-11095. doi: 10.1073/pnas.1508259112

Liu, F., Shi, J., Tanimukai, H., Gu, J., Gu, J., Grundke-Iqbal, I., et al. (2009). Reduced O-GlcNAcylation links lower brain glucose metabolism and Tau pathology in Alzheimer's disease. Brain 132, 1820-1832. doi: 10.1093/brain/awp099

Liu, X., Kim, C. S., Kurbanov, F. T., Honzatko, R. B., and Fromm, H. J. (1999). Dual mechanisms for glucose 6-phosphate inhibition of human brain hexokinase. J. Biol. Chem. 274, 31155-31159. doi: 10.1074/jbc.274.44.31155

McCall, A. L., Van Bueren, A. M., Moholt-Siebert, M., Cherry, N. J., and Woodward, W. R. (1994). Immunohistochemical localization of the neuronspecific glucose transporter (GLUT3) to neuropil in adult rat brain. Brain Res. 659, 292-297. doi: 10.1016/0006-8993(94)90896-6

McCormick, D. A., Connors, B. W., Lighthall, J. W., and Prince, D. A. (1985). Comparative electrophysiology of pyramidal and sparsely spiny stellate neurons of the neocortex. J. Neurophysiol. 54, 782-806. doi: 10.1152/jn.1985.54.4.782

McEwen, B. S., and Reagan, L. P. (2004). Glucose transporter expression in the central nervous system: relationship to synaptic function. Eur. J. Pharmacol. 490, 13-24. doi: 10.1016/j.ejphar.2004.02.041

Miki, T., Liss, B., Minami, K., Shiuchi, T., Saraya, A., Kashima, Y., et al. (2001). ATP-sensitive $\mathrm{K}+$ channels in the hypothalamus are essential for the maintenance of glucose homeostasis. Nat. Neurosci. 4, 507-512. doi: 10.1038/ 87455

Mosconi, L. (2005). Brain glucose metabolism in the early and specific diagnosis of Alzheimer's disease. FDG-PET studies in MCI and AD. Eur. J. Nucl. Med. Mol. Imaging 32, 486-510. doi: 10.1007/s00259-005-1762-7

Mosconi, L., Berti, V., Glodzik, L., Pupi, A., De, S. S., and de Leon, M. J. (2010). Pre-clinical detection of Alzheimer's disease using FDG-PET, with or without amyloid imaging. J. Alzheimers Dis. 20, 843-854. doi: 10.3233/JAD-2010091504

Nagamatsu, S., Kornhauser, J. M., Burant, C. F., Seino, S., Mayo, K. E., and Bell, G. I. (1992). Glucose transporter expression in brain. cDNA sequence of mouse GLUT3, the brain facilitative glucose transporter isoform, and identification of sites of expression by in situ hybridization. J. Biol. Chem. 267, 467-472.

Nehlig, A. (1999). Age-dependent pathways of brain energy metabolism: the suckling rat, a natural model of the ketogenic diet. Epilepsy Res. 37, 211-221. doi: 10.1016/S0920-1211(99)00073-X

Nehlig, A., and Pereira de Vasconcelos, A. (1993). Glucose and ketone body utilization by the brain of neonatal rats. Prog. Neurobiol. 40, 163-221. doi: 10.1016/0301-0082(93)90022-K

Nicholson, R. M., Kusne, Y., Nowak, L. A., LaFerla, F. M., Reiman, E. M., and Valla, J. (2010). Regional cerebral glucose uptake in the 3xTG model of Alzheimer's disease highlights common regional vulnerability across AD mouse models. Brain Res. 1347, 179-185. doi: 10.1016/j.brainres.2010.05.084

Ninfali, P., Aluigi, G., and Pompella, A. (1998). Postnatal expression of glucose6-phosphate dehydrogenase in different brain areas. Neurochem. Res. 23, 1197-1204. doi: 10.1023/A:1020734203128

Oddo, S., Caccamo, A., Shepherd, J. D., Murphy, M. P., Golde, T. E., Kayed, R., et al. (2003). Triple-transgenic model of Alzheimer's disease with plaques and tangles: intracellular A beta and synaptic dysfunction. Neuron 39, 409-421. doi: 10.1016/S0896-6273(03)00434-3

Sabri, M. I., and Ochs, S. (1971). Inhibition of glyceraldehyde-3-phosphate dehydrogenase in mammalian nerve by iodoacetic acid. J. Neurochem. 18, 1509-1514. doi: 10.1111/j.1471-4159.1971.tb00013.x

Sancheti, H., Kanamori, K., Patil, I., Diaz, B. R., Ross, B. D., and Cadenas, E. (2014a). Reversal of metabolic deficits by lipoic acid in a triple transgenic mouse model of Alzheimer's disease: a 13C NMR study. J. Cereb. Blood Flow Metab. 34, 288-296. doi: 10.1038/jcbfm.2013.196

Sancheti, H., Patil, I., Kanamori, K., Diaz, B. R., Zhang, W., Lin, A. L., et al. (2014b). Hypermetabolic state in the 7-month-old triple transgenic mouse model of 
Alzheimer's disease and the effect of lipoic acid: a C-NMR study. J. Cereb. Blood Flow Metab. 34, 1749-1760. doi: 10.1038/jcbfm.2014.137

Sanguinetti, E., Collado, M. C., Marrachelli, V. G., Monleon, D., Selma-Royo, M., Pardo-Tendero, M. M., et al. (2018). Microbiome-metabolome signatures in mice genetically prone to develop dementia, fed a normal or fatty diet. Sci. Rep. 8:4907. doi: 10.1038/s41598-018-23261-1

Sarkar, S., Jun, S., Rellick, S., Quintana, D. D., Cavendish, J. Z., and Simpkins, J. W. (2016). Expression of microRNA-34a in Alzheimer's disease brain targets genes linked to synaptic plasticity, energy metabolism, and resting state network activity. Brain Res. 1646, 139-151. doi: 10.1016/j.brainres.2016.05.026

Schmidt, M. M., and Dringen, R. (2009). Differential effects of iodoacetamide and iodoacetate on glycolysis and glutathione metabolism of cultured astrocytes. Front. Neuroenergetics 1:1. doi: 10.3389/neuro.14.001.2009

Silver, I. A., and Erecinska, M. (1994). Extracellular glucose concentration in mammalian brain: continuous monitoring of changes during increased neuronal activity and upon limitation in oxygen supply in normo-, hypo-, and hyperglycemic animals. J. Neurosci. 14, 5068-5076. doi: 10.1523/JNEUROSCI. 14-08-05068.1994

Simpson, I. A., Carruthers, A., and Vannucci, S. J. (2007). Supply and demand in cerebral energy metabolism: the role of nutrient transporters. J. Cereb. Blood Flow Metab. 27, 1766-1791. doi: 10.1038/sj.jcbfm. 9600521

Small, G. W., Ercoli, L. M., Silverman, D. H., Huang, S. C., Komo, S., Bookheimer, S. Y., et al. (2000). Cerebral metabolic and cognitive decline in persons at genetic risk for Alzheimer's disease. Proc. Natl. Acad. Sci. U.S.A. 97, 6037-6042. doi: 10.1073/pnas.090106797

Sokoloff, L., Reivich, M., Kennedy, C., Des Rosiers, M. H., Patlak, C. S., Pettigrew, K. D., et al. (1977). The [14C]deoxyglucose method for the measurement of local cerebral glucose utilization: theory, procedure, and normal values in the conscious and anesthetized albino rat. J. Neurochem. 28, 897-916. doi: 10.1111/ j.1471-4159.1977.tb10649.x

Sotelo-Hitschfeld, T., Niemeyer, M. I., Machler, P., Ruminot, I., Lerchundi, R., Wyss, M. T., et al. (2015). Channel-mediated lactate release by k+-stimulated astrocytes. J. Neurosci. 35, 4168-4178. doi: 10.1523/JNEUROSCI.5036-14.2015

Surin, A. M., Khiroug, S., Gorbacheva, L. R., Khodorov, B. I., Pinelis, V. G., and Khiroug, L. (2012). Comparative analysis of cytosolic and mitochondrial ATP synthesis in embryonic and postnatal hippocampal neuronal cultures. Front. Mol. Neurosci. 5:102. doi: 10.3389/fnmol.2012.00102

Takanaga, H., Chaudhuri, B., and Frommer, W. B. (2008). GLUT1 and GLUT9 as major contributors to glucose influx in HepG2 cells identified by a high sensitivity intramolecular FRET glucose sensor. Biochim. Biophys. Acta 1778, 1091-1099. doi: 10.1016/j.bbamem.2007.11.015

Tantama, M., Martinez-Francois, J. R., Mongeon, R., and Yellen, G. (2013). Imaging energy status in live cells with a fluorescent biosensor of the intracellular ATP-to-ADP ratio. Nat. Commun. 4:2550. doi: 10.1038/ncomms3550

Tasic, B., Menon, V., Nguyen, T. N., Kim, T. K., Jarsky, T., Yao, Z., et al. (2016). Adult mouse cortical cell taxonomy revealed by single cell transcriptomics. Nat. Neurosci. 19, 335-346. doi: 10.1038/nn.4216

Thevenaz, P., Ruttimann, U. E., and Unser, M. (1998). A pyramid approach to subpixel registration based on intensity. IEEE Trans. Image Process. 7, 27-41. doi: $10.1109 / 83.650848$

Tricoire, L., Pelkey, K. A., Daw, M. I., Sousa, V. H., Miyoshi, G., Jeffries, B., et al. (2010). Common origins of hippocampal ivy and nitric oxide synthase expressing neurogliaform cells. J. Neurosci. 30, 2165-2176. doi: 10.1523/ JNEUROSCI.5123-09.2010
Vaishnavi, S. N., Vlassenko, A. G., Rundle, M. M., Snyder, A. Z., Mintun, M. A., and Raichle, M. E. (2010). Regional aerobic glycolysis in the human brain. Proc. Natl. Acad. Sci. U.S.A. 107, 17757-17762. doi: 10.1073/pnas.1010459107

Vannucci, S. J., and Simpson, I. A. (2003). Developmental switch in brain nutrient transporter expression in the rat. Am. J. Physiol. Endocrinol. Metab. 285, E1127-E1134. doi: 10.1152/ajpendo.00187.2003

Vaughn, A. E., and Deshmukh, M. (2008). Glucose metabolism inhibits apoptosis in neurons and cancer cells by redox inactivation of cytochrome c. Nat. Cell Biol. 10, 1477-1483. doi: 10.1038/ncb1807

Vilchez, D., Ros, S., Cifuentes, D., Pujadas, L., Valles, J., Garcia-Fojeda, B., et al. (2007). Mechanism suppressing glycogen synthesis in neurons and its demise in progressive myoclonus epilepsy. Nat. Neurosci. 10, 1407-1413. doi: 10.1038/ nn1998

Vlassenko, A. G., Vaishnavi, S. N., Couture, L., Sacco, D., Shannon, B. J., Mach, R. H., et al. (2010). Spatial correlation between brain aerobic glycolysis and amyloid-\{beta\} (A $\{$ beta\}) deposition. Proc. Natl. Acad. Sci. U.S.A. 107, 17763-17767. doi: 10.1073/pnas.1010461107

Wilkin, G. P., and Wilson, J. E. (1977). Localization of hexokinase in neural tissue: light microscopic studies with immunofluorescence and histochemical procedures. J. Neurochem. 29, 1039-1051. doi: 10.1111/j.1471-4159.1977. tb06507.x

Winkler, E. A., Nishida, Y., Sagare, A. P., Rege, S. V., Bell, R. D., Perlmutter, D., et al. (2015). GLUT1 reductions exacerbate Alzheimer's disease vasculo-neuronal dysfunction and degeneration. Nat. Neurosci. 18, 521-530. doi: 10.1038/nn.3966 Yamamoto, K., Ueta, Y., Wang, L., Yamamoto, R., Inoue, N., Inokuchi, K., et al. (2011). Suppression of a neocortical potassium channel activity by intracellular amyloid-beta and its rescue with Homerla. J. Neurosci. 31, 11100-11109. doi: 10.1523/JNEUROSCI.6752-10.2011

Yang, X. J., Kow, L. M., Funabashi, T., and Mobbs, C. V. (1999). Hypothalamic glucose sensor: similarities to and differences from pancreatic beta-cell mechanisms. Diabetes Metab. Res. Rev. 48, 1763-1772. doi: 10.2337/diabetes. 48.9.1763

Yao, J., Irwin, R. W., Zhao, L., Nilsen, J., Hamilton, R. T., and Brinton, R. D. (2009). Mitochondrial bioenergetic deficit precedes Alzheimer's pathology in female mouse model of Alzheimer's disease. Proc. Natl. Acad. Sci. U.S.A. 106, 14670-14675. doi: 10.1073/pnas.0903563106

Zeisel, A., Manchado, A. B., Codeluppi, S., Lonnerberg, P., La, M. G., Jureus, A., et al. (2015). Cell types in the mouse cortex and hippocampus revealed by single-cell RNA-seq. Science 347, 1138-1142. doi: 10.1126/science.aaa1934

Zeitschel, U., Bigl, M., Eschrich, K., and Bigl, V. (1996). Cellular distribution of 6phosphofructo-1-kinase isoenzymes in rat brain. J. Neurochem. 67, 2573-2580. doi: $10.1046 / \mathrm{j} .1471-4159.1996 .67062573 . x$

Conflict of Interest Statement: The authors declare that the research was conducted in the absence of any commercial or financial relationships that could be construed as a potential conflict of interest.

Copyright @ 2018 Piquet, Toussay, Hepp, Lerchundi, Le Douce, Faivre, Guiot, Bonvento and Cauli. This is an open-access article distributed under the terms of the Creative Commons Attribution License (CC BY). The use, distribution or reproduction in other forums is permitted, provided the original author(s) and the copyright owner(s) are credited and that the original publication in this journal is cited, in accordance with accepted academic practice. No use, distribution or reproduction is permitted which does not comply with these terms. 